WHOI-90-18

IMET TR-90-02

COPY 1

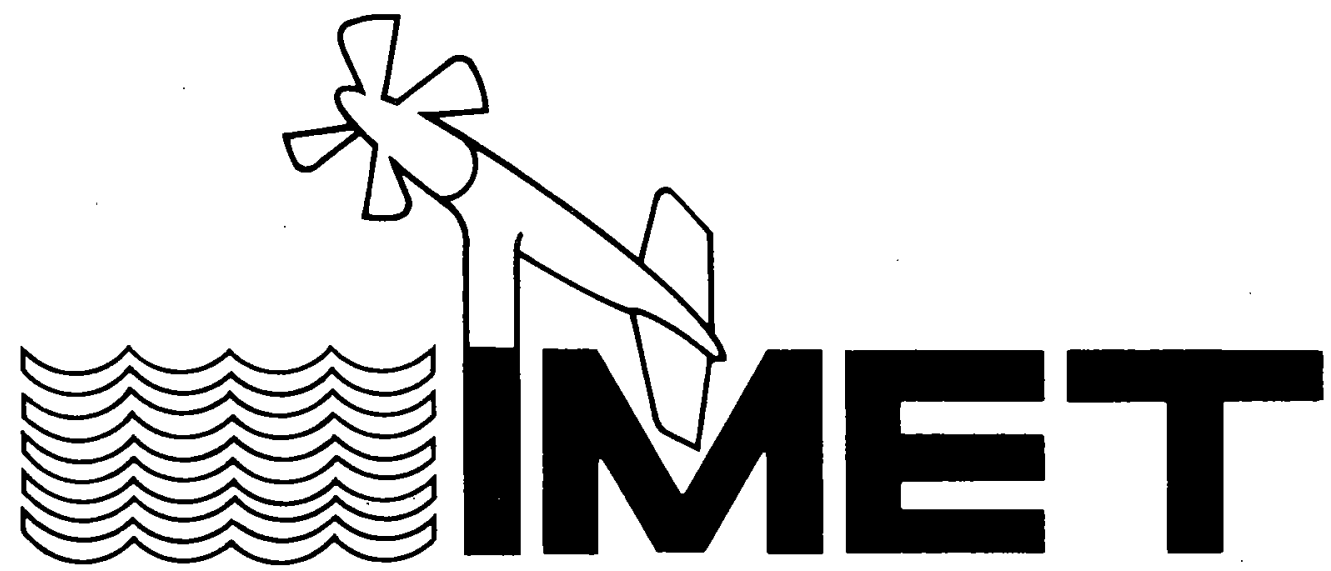

Improved Meteorological Measurements from Buoys and Ships

\title{
Improved Meteorological Measurements from Buoys and Ships (IMET): Preliminary Comparison of Humidity Sensors
}

by

Gennaro H. Crescenti, Richard E. Payne, and Robert A. Weller May 1990

\section{Technical Report}

Funding was provided by the National Science Foundation under Grant No. OCE-87-09614.

Approved for public release; distribution unlimited.

DOCUMENT

LIBRARY

Woods Hole Oceanographic

Institution 
WHOI-90-18

IMET TR-90-02

\section{Improved Meteorological Measurements from Buoys and Ships (IMET): Preliminary Comparison of Humidity Sensors}

by

Gennaro H. Crescenti, Richard E. Payne, and Robert A. Weller

Woods Hole Oceanographic Institution

Woods Hole, Massachusetts 02543

May 1990

Technical Report

Funding was provided by the National Science Foundation under Grant No. OCE-87-09614

Reproduction in whole or in part is permitted for any purpose of the United States Government. This report should be cited as:

Woods Hole Oceanog. Inst. Tech. Rept., WHOI-90-18, IMET TR-90-02.

Approved for publication; distribution unlimited.

Approved for Distribution:

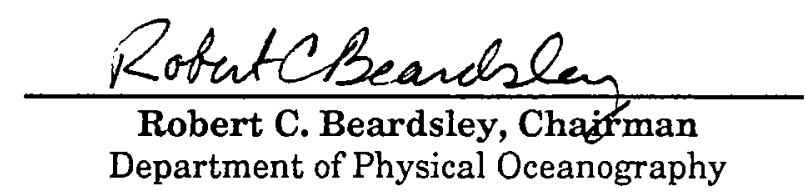




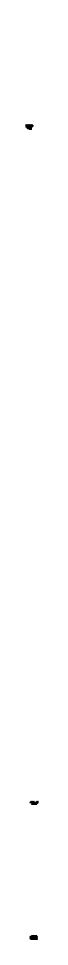




\begin{abstract}
Humidity sensors using various principles of operation are evaluated for the potential use at sea on buoys and ships. Thin film capacitive polymer sensors include the Vaisala Humicap HMP-14U (with WHOI electronics), Hy-Cal Engineering Ultra-H (also with WHOI electronics), the new Vaisala HMP-35A, and the Rotronic MP-100F. Impedance sensors include the Thunder Scientific PC-2101, Phys-Chem PCRC-11, and the General Eastern 850. The Hygrometrix 8503A is the only, organically based cellulose crystallite sensor evaluated. Chilled mirror dew sensors include the EG\&G 200M Dewtrak, which was used as a comparative standard, the General Eastern Dew-10 and the WHOI D10IQ Intelligent Dew Point Sensor. The IR-200 infrared optical hygrometer from Ophir is also included in this study. The performance of the EG\&G 200M Dewtrak was quite disappointing. Errors of up to $2.5^{\circ} \mathrm{C}$ in air temperature were observed due to inadequate shielding from solar radiation.
\end{abstract}




\section{Table of Contents}

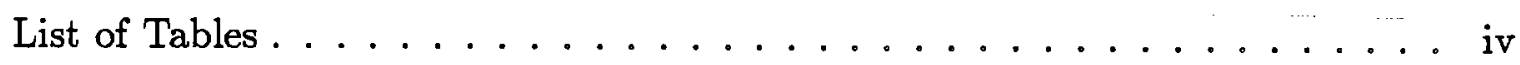

List of Figures $\ldots \ldots \ldots \ldots \ldots \ldots \ldots \ldots \ldots \ldots$

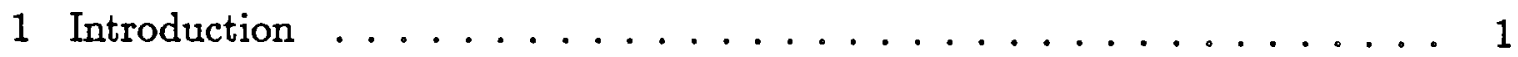

2 Description of Sensors . . . . . . . . . . . . . . 2

2.1 Sensors Not Suitable for IMET . . . . . . . . . . . 3

2.2 Thin Film Capacitive Polymer Sensors . . . . . . . . . . 5

$2.3 \quad$ Impedance Sensors . . . . . . . . . . . . . . . 6

2.4 Cellulose Crystallite Sensors . . . . . . . . . . . . . 6

2.5 Chilled Mirror Dew Point Sensors _ . . . . . . . . . 7

2.6 Optical Hygrometers . . . . . . . . . . . . . 9

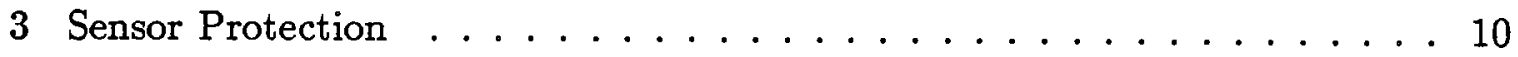

4 Data . . . . . . . . . . . . . . . . . 10

5 Sensor Evaluation Results . . . . . . . . . . . . . . . . . . 11

$5.1 \quad$ Laboratory Tests . . . . . . . . . . . . . . . 11

5.1.1 Thunder Scientific PC-2101 . . . . . . . . . 11

5.1.2 Phys-Chem PCRC-11 . . . . . . . . . . . . 12

$5.1 .3 \quad$ Hygrometrix $8503 \mathrm{~A} \ldots \ldots \ldots \ldots$

5.2 Environmental Tests . . . . . . . . . . . . . . 13

$5.2 .1 \quad \mathrm{Hy}-\mathrm{Cal}$ Engineering $\ldots \ldots \ldots \ldots$

5.2 .2 Vaisala HMP-14U . . . . . . . . . . . 14

$5.2 .3 \quad$ Vaisala HMP-35A . . . . . . . . . . . . 14

5.2 .4 Rotronic MP-100F . . . . . . . . . . . . 15

$5.2 .5 \quad$ General Eastern $850 \ldots \ldots \ldots \ldots$

5.2.6 General Eastern Dew-10 . . . . . . . . . . 16 
$5.2 .7 \quad$ WHOI D10IQ $\ldots \ldots \ldots \ldots \ldots \ldots \ldots$

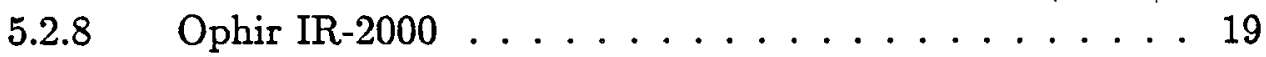

6 Summary and Conclusions . . . . . . . . . . . . . . . . . 19

Acknowledgements . . . . . . . . . . . . . . . . 21

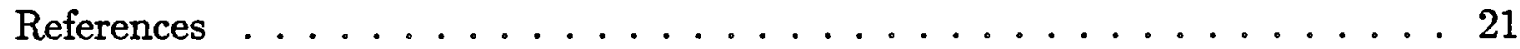

Tables . . . . . . . . . . . . . . . . . . . 25

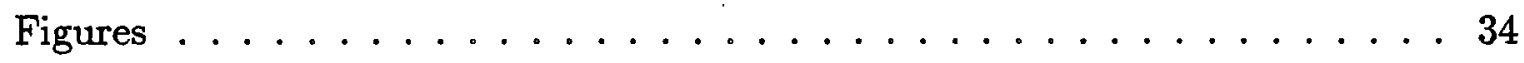

Appendix - Manufacturers' Addresses . . . . . . . . . . . 57 


\section{List of Tables}

1: Performance Criteria of Humidity Sensors . . . . . . . . . . . . . 25

2: Manufacturers' Specifications of Thin Film Capacitive Polymer Sensors . 26

3: Manufacturers' Specifications of Impedance Sensors . . . . . . . . . . . . . 27

4: Calibration coefficients for $\mathrm{Hy}-\mathrm{Cal}$ Engineering Ultra- $\mathrm{H}$ relative humidity sensors . . . . . . . . . . . . . . . . . . . . . 28

5: Calibration coefficients for Vaisala HMP-14U Humicap relative humidity sensors . . . . . . . . . . . . . . . . . . . 29

6: Calibration coefficients for Vaisala HMP-35A relative humidity sensors . . 30

7: Calibration coefficients for Rotronic MP-100F relative humidity sensors . 31

8: Calibration coefficients for General Eastern 850 relative humidity sensors . 33 


\section{List of Figures}

Figure 1: Calibration curves for Thunder Scientific PC-2101 relative humidity sensor. . . . . . . . . . . . . . . . . . . 34 Figure 2: Calibration curve for Phys-Chem PCRC-11 relative humidity sensor. . . . . . . . . . . . . . . . . . . . . 35

Figure 3: Calibration curve for Hygrometrix 8503A relative humidity sensor. 36 Figure 4: Scatter plot of a $\mathrm{Hy}$-Cal Engineering relative humidity sensor compared against a Rotronic MP-100F relative humidity sensor. . . . . . . 37

Figure 5: Calibration curves for $\mathrm{Hy}-\mathrm{Cal}$ Engineering relative humidity sensors. . . . . . . . . . . . . . . . . . . 38

Figure 6: Scatter plots of two Vaisala Humicap relative humidity sensors. . 39

Figure 7: Calibration curves for Vaisala Humicap relative humidity sensors. 40 Figure 8: Calibration curves for Vaisala HMP-35A relative humidity sensors. . . . . . . . . . . . . . . . . . . . . . . 41

Figure 9: Scatter plots for two Vaisala HMP-35A relative humidity sensors. 42 Figure 10: Calibration curves for Rotronic MP-100F relative humidity sensors. . . . . . . . . . . . . . . . . . . . 44 43

Figure 11: Calibration curves for Rotronic MP-100F relative humidity sensors. . . . . . . . . . . . . . . . . . . . . . . . . . 44

Figure 12: Scatter plots for two Rotronic MP-100F relative humidity sensors. . . . . . . . . . . . . . . . . . . .

Figure 13: Scatter plots of General Eastern 850 relative humidity sensors against an EG\&G Dewtrak dew point sensor. . . . . . . . . . . . . . 46 Figure 14: Calibration curves for General Eastern 850 relative humidity sensors. . . . . . . . . . . . . . . . . . . . . . . 44 47

Figure 15: Time series and scatter plot to compare General Eastern Dew-10 chilled mirror dew pointer and a Rotronic MP-100F relative humidity sensor. 48 Figure 16: Comparison of relative humidity difference between a General Eastern Dew-10 and a Rotronic MP-100F. . . . . . . . . . . . . . . . 49

Figure 17: Time series and scatter plot to compare General Eastern Dew-10 chilled mirror dew point sensor and an EG\&G 200M Dewtrak chilled mirror dew point sensor. . . . . . . . . . . . . . . . . . . 50 Figure 18: Comparison of relative humidity difference between a General Eastern Dew-10 and an EG\&G 200M Dewtrak. . . . . . . . . . . . . . 51 Figure 19: Scatter plot of WHOI D10IQ dew point sensor against an EG\&G $200 \mathrm{M}$ Dewtrak dew point sensor. . . . . . . . . . . . . . . . 52

Figure 20: Time series plot of WHOI D10IQ mirror voltage . . . . . . 5 53 Figure 21: Scatter plot of the dew point difference (WHOI D10IQ minus the EG\&G 200M Dewtrak) as a function of the D10IQ mirror voltage . . . . 54 
Figure 22: Scatter plot of air temperature data measured by the WHOI D10IQ and from a Met One fan ventilated radiation shield. . . . . . . . . 55 Figure 23: Scatter plot of the Ophir IR-200 infrared optical hygrometer against a Rotronic MP-100F relative humidity sensor. . . . . . . . . . . 56 


\section{Introduction}

Several components of the United States effort in the World Ocean Circulation Experiment (WOCE) will require accurate and reliable observations of meteorological parameters from both buoys and ships. A group at Woods Hole Oceanographic Institution (WHOI) is developing and testing instrumentation to provide Improved Meteorological measurements (IMET) to meet the requirements of these WOCE components. Here we report some preliminary results on humidity sensor evaluations.

Accurate measurement of atmospheric humidity both over land and sea has always been challenging. Although new techniques for measuring humidity have been introduced over the past several decades, there has been little increase in the accuracy and only a limited increase in the reliability. This problem is pointed out by McKay (1978). In the past five years calibration stability of some humidity sensors has improved. The majority of users of humidity sensors are the heating, ventilating, and air conditioning industry (Crane and Boole, 1988). There are approximately two hundred companies, both large and small, that manufacture various humidity sensors using tens of different principles (Carr-Brion, 1986; Lainer, 1986). Only a very small number of these companies produce sensors suitable for environmental monitoring.

- Obtaining reliable humidity measurements over the ocean where high humidities and the salty marine environment often lead to the corruption and failure of humidity sensors has been an ongoing challenge (Coantic and Friehe, 1980). For example, meteorological measurements made at the North Sea Hydro-Meteo Measuring Network have a relative humidity accuracy of only $\pm 5 \% \mathrm{RH}$ in the range of 20 to $98 \% \mathrm{RH}$ with a resolution of $1 \% \mathrm{RH}$ ( $\operatorname{van}$ den Enden and Jansen, 1983). No one humidity sensor can satisfy all requirements for use at sea. Certain sensors have much faster time responses than others, other hygrometers have a much better accuracy at high humidity conditions, still others may accurately measure humidity at low ambient air temperatures. 
An IMET goal is to discover a humidity sensor that exhibits long term reliability, accuracy, simplicity of design, operational convenience, calibration stability, and ruggedness to withstand the harsh marine environment. Since high humidity conditions (fog) may persist for long periods of time over the ocean, the sensor must recover rapidly from this exposure without calibration change. An overall accuracy of at least $1.7 \% \mathrm{RH}$ is required for relative humidity. This corresponds to $0.3^{\circ} \mathrm{C}$ error in dew point or $0.25 \mathrm{~g} \mathrm{~kg}^{-1}$ error in specific humidity at approximately $20^{\circ} \mathrm{C}$ air temperature.

In this report we evaluate the performance of several types of humidity sensors. Descriptions of each sensor will be given along with an assessment of its performance.

\section{Description of Sensors}

Atmospheric humidity sensors fall into five general categories (WMO, 1983):

(a) Sensors that use the change in dimensions of hygroscopic substances (e.g., hair hygrometers);

(b) Thermodynamic sensors (e.g., psychrometers);

(c) Sensors whose electrical resistance or capacitance changes with humidity due to absorption or adsorption of water molecules;

(d) Condensation sensors (e.g., dew point hygrometer);

(e) Optical infrared light attenuation sensors.

Table 1 (Brock and Nicolaidis, 1985) lists the general performance criteria and characteristics of the last four sensor types. 


\subsection{Sensors Not Suitable for IMET}

Not all humidity sensors are suited for the marine environment. A brief review of several categories are given along with reasons why we have chosen to reject them.

The first category comprises a group of sensors that use organic materials to determine atmospheric humidity. These materials include hair, cotton fibers, wool, wood chips, feathers, animal membranes, squid skin, and bamboo paper (Lainer, 1986). These hygrometers are simple and relatively cheap, however, they have a slow time response, are subject to large hysteresis effects, have poor linearity, and experience large shifts in calibration with time (Carr-Brion, 1986). In one particular organic hygroscopic hygrometer, condensation was found at subsaturation levels (96\% $\% \mathrm{RH}$ ) on the sensing hair strands and response of the instrument was poor below $40 \% \mathrm{RH}$ (McKay, 1978). Because of their overall poor performance, organic hygrometers are not, with one exception, being considered in IMET testing.

The psychrometer has become a universally accepted technique for measurement of atmospheric humidity (McKay, 1978). Its thermodynamic principles are well understood. The psychrometer is easy to use and is reasonably accurate at high humidities. However, psychrometers require proper care and maintenance for accurate results. The wick on the wet bulb thermometer must be free of any dust, dirt or salts and must be replaced frequently. With continuous use, wicks must be cleaned and replaced weekly (Kimball and Mitchell, 1981). Extreme care must be taken in marine environments where hygroscopic aerosols and salt will alter the measured wet bulb depression when deposited on the wick, leading to significant errors. Salt contamination lowers the vapor pressure at the surface of the wick thereby creating a higher than normal wet bulb temperature (Coantic and Friehe, 1980). The psychrometer does not lend itself easily to a self-contained package for remote or unattended applications. Adequate ventilation and shielding from solar radiation are also essential. Cooling the wet bulb to its full depression is difficult at 
relative humidities below $20 \% \mathrm{RH}$. The psychrometer also fails to determine the correct humidity below $0^{\circ} \mathrm{C}$. Thus, while we have used a psychrometer in IMET tests for comparative checks, such an instrument is not suited for WOCE needs.

Clarke and Painting (1983) have found that lithium chloride sensors are extremely susceptible to surface contamination (especially by salts) which result in significant calibration shifts. Since lithium chloride is hygroscopic, it is easily "washed out" during saturation episodes. This type of sensor would require re-doping in a lithium chloride solution and recalibration on a monthly basis. These sensors also have a very slow time response (about 5 minutes). Their power consumption and ventilation rate required do not suit them for buoy use.

Aluminum oxide sensors are mainly used in process control in extreme temperature and pressure conditions. These sensors have been known to exhibit drifts in calibration which are due to the basic physical structure of the sensor itself (Carr-Brion, 1986). Aluminum oxide sensors were used on several radiosonde packages with success but these data required extensive post-experiment correcting due to a large temperature dependency (Chleck, 1979). The anodization method used in creating these aluminum oxide sensors also causes a reduced time response to the order of 1 minute. Large and Pond (1982) found that an aluminum oxide sensor deteriorated in the marine environment and suffered from hysteresis and temperature sensitivity.

The Lyman-alpha hygrometer was developed at the National Center for Atmospheric Research (NCAR) and is routinely used on research aircraft and instrumented towers (Buck, 1983). It measures ultraviolet light attenuation over a fixed path length and has a time response of 12 milliseconds with a resolution of $0.02^{\circ} \mathrm{C}$ (Buck, 1976). The overall absolute system accuracy, however, is only about $1^{\circ} \mathrm{C}$. The sensor can accurately measure humidity spectra at wavenumbers well into the inertial-convective subrange but can not yield an accurate measurement of the 
humidity variance dissipation rate (Andreas, 1981). Moreover, the Lyman-alpha hygrometer suffers from drifts in calibration (Nelson, 1987) and is not ideal for long term, unattended applications. The instrument tends to be rather bulky and power consumption is another limiting factor. Hence, the Lyman-alpha is better suited for atmospheric boundary layer flux measurements than for long term environmental monitoring.

\subsection{Thin Film Capacitive Polymer Sensors}

Thin film capacitive sensors are one of the more recent technological developments in relative humidity measurement. They were first introduced in the late 1970 s to early $1980 \mathrm{~s}$. The earliest designs were inexpensive but were fragile and easily susceptible to contamination (Crane and Boole, 1988). More recent advances have introduced sensors that are more rugged and resistant to contamination, but with a higher price.

It is known that moisture absorption in polymers can affect its dielectric properties (Denton et al., 1985). The sensor is a small capacitor consisting of polymer sandwiched between a pair of electrodes. Absorption of water molecules into the polymer matrix results in an increase in sensor capacitance which can be related to the relative humidity.

Four thin film capacitive polymer sensors have been evaluated. They are:

- Rotronic MP-100F with Pt 100 RTD

- Vaisala HMP-35A with Pt 100 RTD (This is Vaisala's most recently developed sensor)

- Vaisala HMP-14U sensor with WHOI designed electronics

- Hy-Cal Ultra-H sensor with WHOI designed electronics 
Manufacturers' specifications are listed in Table 2. Their addresses and phone numbers are listed in Appendix.

\subsection{Impedance Sensors}

Impedance sensors measure relative humidity by changes in resistance. As the relative humidity increases, resistance decreases. Three different sensors that measure relative humidity by resistance changes have been evaluated. They include the Phys-Chem PCRC-11, the Thunder Scientific PC-2101, and the General Eastern 850. Table 3 lists the manufacturers' specifications of these sensors.

The Phys-Chem PCRC-11 is constructed of a polystyrene substrate that has a thin hygroscopic surface coating. A transducer can also be included inside the probe to measure air temperature.

The Thunder Scientific PC-2101 measures relative humidity with a solid state thin film semiconductor. The sensor consists of a quartz die mounted on an eight pin transistor header and is enclosed within a stainless steel screen cover. Description of the principles of operation by the manufacturer is vague.

The General Eastern 850 is an interdigitated anode/cathode gold grid imbedded in a bulk polymer which changes resistivity as molecules of water are absorbed. Air temperature is measured with a bead thermistor. The 850 has been developed for indoor and industrial applications but has been used in an outdoor environment with some success (Hosom et al., 1988).

\subsection{Cellulose Crystallite Sensors}

Only one organically based humidity sensor was considered. The Hygrometrix $8503 \mathrm{~A}$ has been available for several decades, however, there has been very little published on it. Fenner (1973) does discuss this sensor in detail. The Xeritron humidity sensor is described by the manufacturer as "a composite of organic and 
inorganic crystals which measure humidity by the hygromechanical stress of small but powerful, inert cellulose crystallite structures acting on a metal beam to which a pair of thermally-matched, environmentally-isolated, silicon strain gauges are bonded in a half Wheatstone bridge configuration." The air temperature element is a composite device consisting of a pair of precision thermistors. The stainless steel probe is relatively small measuring 3 inches long and $3 / 8$ inches in diameter.

The Hygrometrix has a specified accuracy of $3 \% \mathrm{RH}$ in a measurement range from 0 to $100 \% \mathrm{RH}$. The response time of the sensor is 3 seconds with a linear uncertainty of $2 \% \mathrm{RH}$ and hysteresis error of $2 \% \mathrm{RH}$ and is quoted to be repeatable to within $1 \% \mathrm{RH}$.

\subsection{Chilled Mirror Dew Point Sensors}

These sensors measure dew point temperature which is a primary measurement of atmospheric water vapor content. Chilled mirror dew point sensors can have an excellent accuracy over a dynamic range that is typical of the marine environment. Dew formation is detected optically as a miniature thermoelectric heat pump cools a metallic mirror while ambient air is drawn past it. A thin dew layer condenses on the mirror surface when the temperature reaches the dew point. Feedback loops continuously control the mirror temperature to within a few tenths of a degree. Some chilled mirror dew point sensors may also be equipped with air temperature sensors so that other humidity quantities (e.g., relative humidity, absolute humidity, mixing ratio) may be calculated.

The EG\&G 200M Dewtrak Humidity Meteorological System was intended to be used as a standard with which to compare the other humidity sensors. The accuracy specified by the manufacturer for dew point measurement is $\pm 0.25^{\circ} \mathrm{C}$ in a range from -50 to $60^{\circ} \mathrm{C}$. Ambient air temperature is also measured by a platinum resistance thermometer in a range from -75 to $60^{\circ} \mathrm{C}$ at the same accuracy. 
Two other chilled mirror dew point sensors are evaluated. The General Eastern Dew-10 Dew Point Transmitter is a low cost sensor designed primarily for heating, ventilating and air conditioning applications but it has been adapted for outdoor use in previous tests (Hosom et al., 1988). The specified accuracy of the Dew-10 is $\pm 0.5^{\circ} \mathrm{C}$ in a range from $-40^{\circ} \mathrm{C}$ to $70^{\circ} \mathrm{C}$. This sensor is not equipped with an air temperature sensor.

Favorable test results and inherent qualities of chilled mirror dew point sensors lead to the design of a microprocessor-controlled instrument based on the General Eastern Dew-10 at WHOI (Hosom et al., 1988). The design goal of the D10IQ is to make high quality measurements for a period of up to one year from an unattended platform near the sea surface while consuming as little power as possible. The sensor was built to withstand the harsh marine environment while retaining the necessary measurement accuracy. The sensor also incorporates a patented self cleaning process known as the "pacer cycle" that was developed by General Eastern to minimize the effects of water soluble dirt deposited on the mirror. Cleaning of the mirror is achieved by cooling and heating the mirror which leaves particulate matter concentrated in small patches. A rotating sleeve was incorporated into the D10IQ as additional protection from aerosols which allows a small port into the sensor head cavity to be opened during the measurement cycle and closed at other times. A quantitative measure of mirror condition is the mirror voltage which is proportional to the light reflected from the mirror to the photo receiver.

At the start of the measurement cycle the D10IQ program causes the rotating sleeve to open. Power is applied to the D10IQ and the aspirating fan which draws in ambient air. The ambient air temperature is then measured and the pacer cycle is initiated. Once the pacer cycle and rebalancing are complete, the mirror voltage is measured. Next, software-controlled feedback loops cool the mirror until it reaches the dew point temperature. Once the dew point is successfully measured, the 
aspirating fan is turned off, the rotating sleeve is closed, and the power to the Dew-10 is turned off. The minimum required time for a complete measurement cycle is 3.5 minutes. In this study the dew point is measured once per hour.

The overall cost of the D10IQ is estimated at approximately $\$ 3200$ in materials plus approximately 300 hours of labor for assembly. Nominal system accuracy is estimated at $\pm 0.3^{\circ} \mathrm{C}$ (Hosom et al., 1988).

\subsection{Optical Hygrometers}

All of the previously mentioned sensors rely on intimate physical contact between the sensing element and the moist air. Optical hygrometers measure the water vapor content in the air by light attenuation. Although determining atmospheric humidity by spectroscopic methods is not new (e.g., Bogomolova et al., 1974; Buck, 1976; Raupach, 1978), the first commercially manufactured sensor has only recently become available.

The Ophir IR-2000 is an infrared optical hygrometer that operates by taking differential infrared absorption measurements both near and within the mid-infrared water vapor absorption band centered at 2.67 microns (Cerni et al., 1987). This fast response sensor measures infrared light attenuation over a fixed path length and relates the transmission to absolute humidity $\left(\mathrm{g} \mathrm{m}^{-3}\right)$ or dew point. The IR-2000 may not suffer from stability problems (Nelson, 1987). The optical windows are constructed from nonhygroscopic materials which allow the sensor to become wet from sea spray, rain or condensation without damage or calibration shift.

The manufacturer states that the dew point temperature accuracy of the IR-2000 is $\pm 1.0^{\circ} \mathrm{C}$ from 0 to $40^{\circ} \mathrm{C}$ and $\pm 1.5^{\circ} \mathrm{C}$ from -40 to $0^{\circ} \mathrm{C}$. The sensor can sample humidity data up to a rate of $10 \mathrm{~Hz}$. Although the IR-2000 does not meet the IMET criteria for absolute sensor accuracy, the technique shows promise for use at sea. 


\section{Sensor Protection}

Most of the relative humidity sensor elements are protected from salt contamination with Gore-Tex filters. The expanded Teflon membrane, which has a typical pore size of approximately 5 microns, allows the passage of air and water vapor but not salt or liquid water. Its slick surface helps minimize adhesion of salt crystals. The shield is fashioned roughly as a cylindrical sock over the sensing element. Gore-Tex is also used to filter out contaminants in the General Eastern Dew-10 and the WHOI D10IQ so that dirt and salt do not accumulate on the mirrors. The filter does not significantly reduce the time response of the sensor. The Rotronic MP-100F comes equipped with a rigid porous membrane filter with similar properties which also seems quite effective.

\section{Data}

Outdoor environmental testing of humidity sensors was conducted on the roof of the Smith Building in Woods Hole, Massachusetts $\left(41^{\circ} 31.5^{\prime} \mathrm{N}, 70^{\circ} 40.0^{\prime} \mathrm{W}\right)$. Calibrations and laboratory tests were conducted at a WHOI calibration facility.

Most of these data from sensors placed outdoors were acquired on two computer systems. The first system was a PC AT compatible microcomputer with an Analog Devices RTI-800 12-bit analog-to-digital (A/D) board. Data were collected from May 1988 to March 1989 on this system. The second system was developed to allow a more diverse selection of instruments for testing. This system utilizes the same microcomputer with a Metra-Byte 12-bit A/D board. Data have been recorded from March 1989 and recording continues as of this writing. Data are sampled at $1 \mathrm{~Hz}$ and recorded as 7.5 minute averages in both systems.

The only exception is the WHOI D10IQ which measured the dew point once per hour and was recorded independently from the above mentioned computer systems. 


\section{Sensor Evaluation Results}

Nearly all of the humidity sensors (except for the dew point sensors and the optical hygrometer) were first evaluated in the calibration chamber before being placed outdoors for environmental testing. Sensors that displayed unacceptable behavior were dismissed from further tests and are discussed in section 5.1. Sensors that showed good behavior characteristics were included in the outdoor tests and are discussed in section 5.2 .

The EG\&G 200M Dewtrak was purchased to use as a basis of comparison for air and dew point temperature as well as relative humidity. Its performance has been disappointing since it is poorly shielded from solar radiation. Errors in air temperature measurement have been observed to be as large as $2.5^{\circ} \mathrm{C}$.

In spite of this we have used the Dewtrak data to compute relative humidities expecting little or no long term drift in absolute values. With this assumption, these data were still valuable to determine long term drifts in the relative humidity sensors. Partly in response to our comments, EG\&G has partially redesigned the radiation shield and we are awaiting delivery of our modified unit.

\subsection{Laboratory Tests}

\subsubsection{Thunder Scientific PC-2101}

The Thunder Scientific PC-2101 relative humidity sensors were found to be extremely nonlinear, to have poor hysteresis characteristics and to possess large temperature dependencies. Figure 1 shows calibration points determined by Thunder Scientific and by WHOI. Both sensors showed a shift even though they were not used between the two calibrations. A third order polynomial was fitted to the WHOI calibration points and rms errors were found between 4.0 to $4.5 \% \mathrm{RH}$ of the fit. Other functions (i.e., exponential, logarithmic, and power) fitted even more poorly. 
Both sensors displayed poor hysteresis, overestimating the relative humidity by 10 to $11 \% \mathrm{RH}$ after nearly 24 hours in the calibration chamber following a relative humidity decrease from 90 to $50 \% \mathrm{RH}$. In addition to large hysteresis, Large and Pond (1982) also found unacceptable temperature sensitivities.

\subsubsection{Phys-Chem PCRC-11}

The Phys-Chem PCRC-11 sensor was also found to be extremely nonlinear and to have a large temperature dependence. A calibration fit computed at WHOI is poor (Figure 2). Although the sensor has been used in the North Sea in the United Kingdom offshore buoy observing network (Clarke and Painting, 1983), we found the sensor unsatisfactory for WOCE needs. Typical rms errors were found by Clarke and Painting to be $\pm 2.5 \% \mathrm{RH}$ with an undesirable temperature coefficient of $-0.4 \% \mathrm{RH} \mathrm{C} \mathrm{C}^{-1}$. Sea salt contamination resulted in sensor failure.

\subsubsection{Hygrometrix 8503A}

The Hygrometrix 8503A humidity sensor was calibrated at WHOI upon its receipt. The third order polynomial calibration curve fit (Figure 3 ) shows that the sensor is insensitive at humidities below $20 \% \mathrm{RH}$ and above $90 \% \mathrm{RH}$. Upon. completion of the calibration, the humidity in the chamber was quickly dropped from 90 to $50 \% \mathrm{RH}$ to examine hysteresis effects. Humidity values from the Hygrometrix were approximately $5.5 \% \mathrm{RH}$ high after 3 hours while the humidity inside the chamber was maintained at $50 \% \mathrm{RH}$. We have not carried out further tests since this poor hysteresis is unacceptable for outdoor monitoring where atmospheric conditions can change quickly.

An early version of this Hygrometrix sensor was used in the Vector Averaging Wind Recorder (Payne, 1974) and was found to have an uncertainty of at least $5 \% \mathrm{RH}$. McKay (1978) found even larger average errors of 10 to $15 \% \mathrm{RH}$ with high 
variability. The sensor has not stood up well to long term exposure to environmental conditions because the strain gauge has not stayed bonded to the crystal in previous versions (Payne, 1974; McKay, 1978). A similar sensor marketed by Hy-Cal Engineering at the time was used in the Coastal Ocean Dynamics Experiment (Dean and Beardsley, 1988) but the relative humidity data were poor and questionable. We conclude from our calibration tests and from previous studies that cellulose crystallite sensors are not appropriate for use at sea.

\subsection{Environmental Tests}

Humidity sensors currently used on WHOI buoys are calibrated before and after each deployment. New humidity sensors are also calibrated at WHOI as a check against factory calibration values.

Most of the sensors tested on the roof have been recalibrated approximately once per month to establish a calibration history. Each time a sensor is brought in for recalibration, the Gore-Tex shield is washed off to remove any salt or dirt.

\subsubsection{Hy-Cal Engineering}

Two Hy-Cal Engineering Ultra-H capacitive polymer sensor elements with WHOI electronics were evaluated (S/N 2 and 3) in the IMET tests. The Hy-Cal sensors exhibited very large drifts in calibration (Table 4) and performed poorly in outdoor comparisons. For example, a scatter plot of a $\mathrm{Hy}$-Cal sensor against a Rotronic MP-100F shows poor agreement (Figure 4). Calibration plots show the random nature of the $\mathrm{Hy}$-Cal sensors (Figure 5). Shifts of up to $50 \% \mathrm{RH}$ are observed for a given output signal between calibrations. The calibration changes appear to be random and abrupt. We have not carried out further evaluations of the Hy-Cal sensors. 


\subsubsection{Vaisala HMP-14U}

Two Vaisala HMP-14U Humicap sensors (S/N A and B) are compared against each other in scatter plots (Figure 6) which show the nonlinear behavior of the two sensors as well as the insensitivity of sensor B at very high humidities. Sensor A exhibited large drifts towards higher humidity values $(>100 \% \mathrm{RH})$. Calibration plots for both these sensors are seen in Figure 7. Because of this insensitivity and drifting of the Humicap sensors (Table 5), no further tests were conducted on these discontinued sensors.

Weller et al. (1990) estimated the overall accuracy of these sensors used in FASINEX (Stage and Weller, 1985; 1986) to be from 2 to $3 \% \mathrm{RH}$ following extensive pre- and post-deployment calibrations. Muller and Beekman (1987) observed that it took the Humicap approximately one week to recover after one day at saturation. Ward (1983) found a repeatability of $1.5 \% \mathrm{RH}$ from 10 to $90 \% \mathrm{RH}$ and estimated the overall uncertainty at $2 \% \mathrm{RH}$ at $20^{\circ} \mathrm{C}$ and $3 \% \mathrm{RH}$ from 10 to $60^{\circ} \mathrm{C}$. Other studies (Visscher and Schurer, 1985; McKay, 1978) have observed shifts in calibration towards higher humidity values with large variability. This behavior was observed on a recent mooring (Kery, 1989) in the Atlantic Ocean southeast of Nova Scotia.

\subsubsection{Vaisala HMP-35A}

Vaisala recently introduced the HMP-35A, an improved version of their Humicap sensor. Several calibrations were conducted over a half year span showing only small shifts in calibration (Figure 8). Both sensors have shown a negative drift at low humidities $(<30 \% \mathrm{RH})$ of approximately $2 \% \mathrm{RH}$ while displaying a positive drift at higher humidities (>80\%RH) of 2 to $4 \% \mathrm{RH}$ (Table 6). Drifting of calibration in moderate humidities is less than $1 \% \mathrm{RH}$.

Scatter plots for each sensor (Figure 9, S/N 287852 and 287855) show good agreement with a standard error of $1 \% \mathrm{RH}$ for each least squares fit. Both sensors 
show a consistent offset of about $-3.5 \% \mathrm{RH}$ when compared against the EG\&G $200 \mathrm{M}$ Dewtrak. Slopes are off by about $3 \%$.

\subsubsection{Rotronic MP-100F}

A series of Rotronic MP-100F sensors (S/N 02388, 02392, 16301, 16302) were evaluated. Calibration curves for these sensors are shown in Figures 10 and 11. In all cases, the Rotronic MP-100F displayed little drift in calibration (Table 7). In most cases, the drift in calibration was positive, eventually leading to overestimates, especially at higher humidities. Overall errors in drift are approximately 2 to $4 \% \mathrm{RH}$ in a six month period for a given output signal.

Figure 12 shows scatter plots for two Rotronic sensors for a one week period compared against the EG\&G Dewtrak. Standard errors of the least squares fit are less than $1.5 \% \mathrm{RH}$. The slopes are sometimes off by up to $10 \%$ and offsets up to $5 \%$ RH.

Past studies (Hundermark, 1989a, 1989b; Muller and Beekman, 1987; Visscher and Schurer, 1985) have shown that the Rotronic does not display the hysteresis effects commonly associated with polymer sensors, even after long periods at saturation. The same has been found to be true in the IMET evaluations. Repeatability was found to be at least $2 \% \mathrm{RH}$ (Muller and Beekman, 1987), and the largest deviations of 10 to $15 \% \mathrm{RH}$ were found at high humidities $(>90 \% \mathrm{RH})$ at very cold temperatures $\left(-20^{\circ} \mathrm{C}\right)$. Semmer (1987) found good agreement up to $90 \% \mathrm{RH}$ in field tests.

\subsubsection{General Eastern 850}

Two General Eastern 850 humidity sensors (S/N 846 and 946) showed better results than the other resistance sensors. A scatter plot of these sensors against the 
EG\&G Dewtrak (Figure 13) displays fair agreement. These sensors also displayed small hysteresis effects in outdoor testing.

Calibration histories have been established for the General Eastern 850 sensors. Several calibrations were performed over a six month period (Table 8). Although shifts in calibration are not usually large between individual calibrations, a significant shift is observed over a long time period (Figure 14). Both sensors have shown a positive drift at higher humidities which results in an overestimation of the relative humidity. Indicated relative humidity values of 105 to nearly $110 \% \mathrm{RH}$ are not uncommon after several months of monitoring using the original calibration information. Sensor 846 showed this positive drift for nearly all humidities with time, however, sensor 946 shows a negative drift, or underestimation of relative humidity, at low humidities with time. This negative drift at $30 \% \mathrm{RH}$ is approximately 3 to $4 \% \mathrm{RH}$. Small changes in calibration shift are observed in moderate humidity conditions (40-60\%RH). Using the original calibration information after nearly six months of environmental monitoring, the General Eastern 850 sensors overestimate the relative humidity from 5 to $8 \% \mathrm{RH}$ at high humidities (>80\%RH). Standard errors from linear least squares fits of both sensors against the EG\&G Dewtrak are less than $2 \% \mathrm{RH}$ with the correct calibration. However, those standard errors increase to approximately $4 \% \mathrm{RH}$ after six months using the original calibration coefficients.

Although the General Eastern 850 was one of the better performing sensors, its drift rates were too high to be acceptable for buoy deployments of six months or longer.

\subsubsection{General Eastern Dew-10}

Although the Dew-10 is not intended for use outdoors, we tested it anyway as an example of a relatively inexpensive dew point sensor. Its performance, however, was 
unsatisfactory. In an early test (summer 1988), dew point data obtained by the Dew-10 were converted into relative humidities and compared against relative humidity data from a Rotronic MP-100F (S/N 11378). The Rotronic exhibited a mean calibration shift of only $0.4 \% \mathrm{RH}$ during the two month period of the comparison.

The Dew-10 showed considerable scatter and uncertainty throughout the test (Figures $15 \mathrm{a}$ and $15 \mathrm{~b}$ ). The standard error to a linear fit is nearly $3 \% \mathrm{RH}$. A probability density function (Figure 16a) was constructed of the relative humidity difference. The amount of scatter exhibited here in this plot is fairly typical of all other weeks during the test. These errors show a dependency on insolation (Figure 16b) but this was probably due to our environmental housing.

The Dew-10 eventually failed at temperatures just below freezing and was removed temporarily from the IMET tests during the winter of $1988 / 1989$. The sensor was sent back to General Eastern for cleaning and recalibration. The results in a second test, however, yielded similar disappointing results. In this instance, the dew point data from the Dew-10 was compared against dew point data from an EG\&G 200M Dewtrak chilled mirror sensor.

A time series and scatter plot shown in Figures $17 \mathrm{a}$ and $17 \mathrm{~b}$ exhibit much of the same poor behavior. A probability density function (Figure 18a) shows the range of variability between the Dew-10 and the Dewtrak. Errors in excess of $8^{\circ} \mathrm{C}$ are not unusual. As before, the dew point temperature difference is strongly correlated with insolation (Figure 18b).

\subsubsection{WHOI D10IQ}

Data from the D10IQ are more encouraging. In a comparison with the EG\&G $200 \mathrm{M}$ Dewtrak, a least squares fit (Figure 19) shows an offset of $-0.2^{\circ} \mathrm{C}$ with a slope of 0.975 and a standard error of $1.2^{\circ} \mathrm{C}$. Figure 20 shows the mirror voltage of the 
D10IQ for approximately five months. The signal slowly drops over the first 3 to 4 months with a very rapid drop in the last month. It was later discovered that the rubber O-rings which hold the Gore-Tex filter in place had disintegrated. Figure 21 shows the dew point difference of the D10IQ and the Dewtrak as a function of mirror voltage. The largest differences in dew point occur between 2.4 to 2.6 volts, slightly higher than the 2.2 volt cut off suggested by Hosom et al. (1988). The errors below 2.2 volts are not significantly larger than the errors observed above 2.2 volts. It should be noted that the largest errors occur at the higher dew points $\left(>15^{\circ} \mathrm{C}\right)$. Unlike the Dew-10, the D10IQ errors appear to be random in nature with no correlation to the ambient air temperature, wind speed or insolation.

The D10IQ also measures ambient air temperature. A scatter plot (Figure 22) of the air temperature measured by the D10IQ against the air temperature measured inside a Met One fan aspirated radiation shield shows a significant amount of scatter. A linear least squares fit shows an offset of $-0.3^{\circ} \mathrm{C}$ with a slope of 1.007 and a standard error of $1.2^{\circ} \mathrm{C}$. While the fit is very good, the scatter of individual air temperature measurements is much too large. This uncertainty shows no dependence on solar heating or on the wind speed. Thus, air temperature measurements with the D10IQ are inadequate.

Although the pacer cycle, in theory, can extend the period of accuracy of a chilled mirror sensor, excessive use of the process may actually serve to hasten, rather than delay, fouling of the mirror when a major contaminant is present on the mirror surface (Hosom et al., 1988). The question also remains of the effectiveness of the Gore-Tex filter. At present a pore size of 5 microns is used on the sensor. Smaller pore sizes would effectively reduce fouling by aerosols that permeate the membrane, however, a larger fan would be needed since the smaller pores would increase the resistance to air flow. 


\subsubsection{Ophir IR-2000}

After its delivery in July 1989, the Ophir IR-2000 underwent outdoor testing with other fast response hygrometers in a joint cooperative effort with the National Oceanic and Atmospheric Administration in Oak Ridge, Tennessee (Meyers, 1989, personal communication). Upon completion of the experiment, the optical hygrometer was returned to WHOI where IMET testing began in late October 1989.

Unfortunately, the Ophir failed in the second week of testing. A design flaw allowed penetration of rain water through the top of a protective aluminum housing into the sensor electronics, ultimately causing a catastrophic failure of the hygrometer. The IR-2000 was returned to Ophir for repairs and improvement of environmental protection.

A scatter plot (Figure 23) shows a comparison of the Ophir hygrometer against a Rotronic humidity sensor (unfortunately during the time that the IR-2000 was operational, the EG\&G Dewtrak was accidentally disconnected from the data acquisition system). Sporadic errors and spikes in the Ophir data were removed before the comparison. Although the least squares fit and the standard error are less than ideal in the scatter plot, the Ophir shows some promise in obtaining atmospheric humidity values. However, this evidence is not conclusive and further testing will be carried out.

\section{Summary and Conclusions}

WOCE requires high quality meteorological measurements from ships and buoys. Obtaining accurate humidity data is critical to our understanding the role of latent heat flux in the marine atmospheric boundary layer.

The Rotronic MP-100F seems to be the best candidate among the thin film capacitive polymer sensors. The new Vaisala HMP-35A also shows much promise but 
more extensive testing will be needed to answer questions on long term reliability and stability. Both of these sensors were specifically developed for outdoor monitoring. The older Vaisala HMP-14U Humicap sensors show large variability and hysteresis problems that have been verified in other studies. The Hy-Cal Engineering sensors show large drifts in calibration with time that are not satisfactory for long term deployment at sea.

The impedance sensors displayed mixed results. The Thunder Scientific PC-2101 showed considerable hysteresis problems and temperature dependency. An adequate calibration curve for the PC-2101 is quite difficult to obtain and this sensor has a large temperature dependency. The General Eastern 850 sensors exhibit large drifts of calibration with time and are probably inadequate for long term deployment at sea.

The Hygrometrix cellulose crystallite sensor displays large hysteresis. Like the Thunder Scientific sensor, obtaining a proper calibration curve to represent extremes in relative humidity, especially greater than $90 \% \mathrm{RH}$, is difficult. This sensor is also unsatisfactory for our needs. Chilled mirror dew point sensors may be able to make accurate measurements with sufficient sampling sophistication. This is evident in the General Eastern Dew-10 which has a very simple, constant sampling scheme, as opposed the D10IQ which is the Dew-10 with added electronics and software. The WHOI D10IQ has performed quite well and may be considered as a candidate for measuring dew point. The unmodified General Eastern Dew-10, however, has performed poorly and it will not be used further.

The Ophir IR-2000 infrared optical hygrometer may prove to be useful but we need to test it further.

Regardless of the type of sensor used to determine the atmospheric humidity, studies show that humidity sensors should be recalibrated approximately once every 6 months (Hundermark, 1989a; Muller, 1985; Clarke and Painting, 1983). With 
careful documentation of calibration histories of each sensor, it may be possible to obtain accurate humidity data over long periods of time at sea.

\section{Acknowledgements}

This work was funded by the National Science Foundation (Grant No. OCE87-09614) as a World Ocean Circulation Experiment (WOCE) long-lead time development activity.

The authors would like to thank David Hosom and James Price for their insights and comments on measuring dew point with the WHOI D10IQ and Ovid Fortier for his help in designing and implementing much of the circuitry for the data acquisition system.

\section{References}

Andreas, E. L., 1981: The effects of volume averaging on spectra measured with a Lyman-alpha hygrometer. Journal of Applied Meteorology, 20, 467-475.

Bogomolova, L. V., V. I. Dianov-Klokov, S. L. Zubkovskiy, 1974: Double-beam infrared spectrometer for measuring humidity fluctuations in the atmosphere. Atmospheric and Oceanic Physics, 10, 933-942.

Brock, F. V., and C. E. Nicolaidis (eds.), 1985: Instructor's Handbook on Meteorological Instrumentation. Atmospheric Technology Division, National Center for Atmospheric Research, NCAR Technical Note NCAR/TN-237+IA.

Buck, A. L., 1976: The variable-path Lyman-alpha hygrometer and its operating characteristics. Bulletin of the American Meteorological Society, 57, 1113-1118.

Buck, A. L., 1983: The Lyman-alpha absorption technique for fast humidity measurement. Fifth Symposium on Meteorological Observations and Instrumentation, Toronto, Canada, American Meteorological Society, pp. 16-20.

Carr-Brion, K., 1986: Moisture Sensors in Process Control. Elsevier Applied Science Publishers, London, 122 pp. 
Cerni, T. A, D. Hauschulz, L. D. Nelson, and D. Rottner, 1987: An atmospheric infrared hygrometer. Sixth Symposium on Meteorological Observations and Instrumentation, New Orleans, Louisiana, American Meteorological Society, pp. 205-208.

Chleck, D., 1979: Measurement of upper atmospheric water vapor made in situ with a new moisture sensor. Geophysical Research Letters, 6, 379-381.

Clarke, C. S., and D. J. Painting, 1983: A humidity sensor for automatic weather stations. Fifth Symposium on Meteorological Observations and Instrumentation, Toronto, Canada, American Meteorological Society, paper 2.6.

Coantic, M., and C. A. Friehe, 1980: Slow-response humidity sensors. In: Air-Sea Interaction, Instruments and Methods, Plenum Press, New York, pp. 399-409.

Crane, J., and D. Boole, 1988: Thin film humidity sensors: A rising technology. Sensors, 5(5).

Dean, J. P., and R. C. Beardsley, 1988: A Vector-Averaging Wind Recorder (VAWR) system for surface meteorological measurements in CODE (Coastal Ocean Dynamics Experiment). Woods Hole Oceanographic Institution, Technical Report, WHOI-88-20, 74 pp.

Denton, D. D., J. B. Camou, and S. D. Senturia, 1985: Effects of moisture uptake on the dielectric permittivity of polyimide films. Proceedings of the 1985 International Symposium on Moisture and Humidity, Washington, D. C., Instrument Society of America, pp. 505-508.

Fenner, R. L., 1973: Use of cellulose cyrstallite structures with solid state strain gages for humidity and moisture. Proceedings of the 1973 International Symposium on Moisture and Humidity, Washington, D. C., Instrument Society of America, pp. 251-252.

Hosom, D. S., C. L. Winget, S. Weisman, D. P. Doucet, and J. F. Price, 1988: Intelligent chilled mirror humidity sensor. Woods Hole Oceanographic Institution Technical Report, WHOI-88-61, 83 pp.

Hundermark, B. W., 1989a: Field evaluation of the Rotronic humidity sensor and the impulsphysik visibility sensor. Proceedings of the Conference and Exposition on Marine Data Systems, New Orleans, Louisiana, Marine Technology Society, pp. 81-85.

Hundermark, B. W., 1989b: Evaluation of humidity and visibility sensors. National Data Buoy Center, Technical Bulletin, 15(1), 8 pp. 
Kery, S. M., 1989: Severe Environment Surface Mooring (SESMOOR). IEEE Marine Technology Society Oceans-89, Seattle.

Kimball, B. A., and S. T. Mitchell, 1981: An accurate, low-maintenance psychrometer. Journal of Applied Meteorology, 20, 1533-1537.

Lainer, B., 1986: Humidity Sensors. Sensors, 3(5).

Large, W. G., and Pond, S., 1982: Sensible and latent heat flux measurements over the ocean. Journal of Physical Oceanography, 12, 464-482.

McKay, D. J., 1978: A sad look at commercial humidity sensors for meteorological applications. Fourth Symposium on Meteorological Observations and Instrumentation, Denver, Colorado, American Meteorological Society, pp. 7-14.

Muller, S. A., 1985: Operational experience at sea locations with a humidity sensor based on the impedance measurement of an electrolyte. Proceedings of the 1985 International Symposium on Moisture and Humidity, Washington, D. C., Instrument Society of America, pp. 643-648.

Muller, S. A., and P. J. Beekman, 1987: A test of commercial humidity sensors for use at automatic weather stations. Journal of Atmospheric and Oceanic Technology, 4, 731-735.

Nelson, L. D., 1987: Atmospheric humidity measurement. Sensors, 4, 21-22.

Payne, R. E., 1974: A buoy-mounted meteorological recording package. Woods Hole Oceanographic Institution Technical Report, WHOI-74-40, 32 pp.

Raupach, M. R., 1978: Infrared fluctuation hygrometry in the atmospheric surface layer. Quarterly Journal of the Royal Meteorological Society, 104, 309-322.

Semmer, S. R., 1987: Evaluation of a capacitance humidity sensor. Sixth Symposium on Meteorological Observations and Instrumentation, New Orleans, Louisiana, American Meteorological Society, pp. 223-225.

Stage, S. A., and R. A. Weller, 1985: The Frontal Air-Sea Interaction Experiment (FASINEX); Part I: Background and Scientific Objectives. Bulletin of the American Meteorological Society, 66, 1511-1520.

Stage, S. A., and R. A. Weller, 1986: The Frontal Air-Sea Interaction Experiment (FASINEX); Part II: Experimental Plan. Bulletin of the American Meteorological Society, 67, 16-20. 
van den Enden, I. F. H. C. C., and R. H. J. Jansen, 1983: The North Sea

Hydro-Meteo Measuring Network and its meteorological instruments. Fifth Symposium on Meteorological Observations and Instrumentation, Toronto, Canada, pp. 568-572.

Visscher, G. J. W., and K. Schurer, 1985: Some research on the stability of several capacitive thin film (polymer) humidity sensors in practice. Proceedings of the 1985 International Symposium on Moisture and Humidity, Washington, D. C., Instrument Society of America, pp. 515-523.

Ward, B. K., 1983: Digital hygrometer with capacitive sensor. Journal of Physics $E, 16,731-733$.

Weller, R. A., D. L. Rudnick, R. E. Payne, J. P. Dean, N. J. Pennington, and R. P. Trask, 1990: Measuring local meteorology and upper ocean variability at an array of surface moorings in the subtropical convergence zone. Journal of Atmospheric and Oceanic Technology, 7, 85-103.

World Meteorological Organization, 1983: Measurement of atmospheric humidity. Guide to Meteorological Instruments and Methods of Observation, Fifth Edition. WMO No. 8. 


\section{Table 1: Performance Criteria of Humidity Sensors (adapted from Brock and Nicolaidis, 1985)}

\begin{tabular}{lcccc} 
& \multicolumn{4}{c}{ Device Class } \\
\cline { 2 - 5 } Criterion & Psychrometer & Sorption & Condensation & Attenuation \\
\hline Cost* $(\$)$ & 150 to 1,000 & 100 to 1,000 & 5,000 & 2,000 to 10,000 \\
Accuracy & $3 \% \mathrm{RH}$ & $2-10 \% \mathrm{RH}$ & $0.5^{\circ} \mathrm{C}$ & $5 \% \mathrm{RH}$ \\
Time Constant (sec) & $0.1-30$ & $10-300$ & 10 & 0.01 \\
$\begin{array}{l}\text { Useful Range (\%RH) } \\
\text { Liquid Water }\end{array}$ & $20-100$ & $5-100$ & $5-100$ & $0-100$ \\
$\quad$ Tolerance & good & poor & excellent & fair/good \\
Field Maintenance & moderate & low & low & low \\
Typical Application & profile & surface & calibration & flux \\
& & station & standard & \\
\hline
\end{tabular}

* Approximate cost for a full system. 
Table 2: Manufacturers' Specifications of Thin Film Capacitive Polymer Sensors

\begin{tabular}{|c|c|c|c|c|}
\hline & $\begin{array}{l}\text { Rotronic } \\
\text { MP-100F }\end{array}$ & $\begin{array}{c}\text { Vaisala } \\
\text { HMP-14U }\end{array}$ & $\begin{array}{l}\text { Vaisala } \\
\text { HMP-35A }\end{array}$ & $\begin{array}{l}\mathrm{Hy}-\mathrm{Cal} \\
\text { Ultra-H }\end{array}$ \\
\hline $\begin{array}{l}\text { Accuracy (\% RH) } \\
25^{\circ} \mathrm{C}\end{array}$ & $\begin{array}{c}2.0 \text { from } \\
0-100 \% \mathrm{RH}\end{array}$ & $\begin{array}{c}2.0 \text { from } \\
0-80 \% \mathrm{RH} \\
3.0 \text { from } \\
80-100 \% \mathrm{RH}\end{array}$ & $\begin{array}{c}2.0 \text { from } \\
0-90 \% \mathrm{RH} \\
\\
3.0 \text { from } \\
90-100 \% \mathrm{RH}\end{array}$ & $\begin{array}{l}2.5 \text { from } \\
0-95 \% \mathrm{RH} \\
.\end{array}$ \\
\hline Linearity (\% RH) & 0.7 & - & - & 1.0 \\
\hline Hysteresis (\% RH) & 0.3 & - & - & 1.0 \\
\hline Repeatability (\% RH) & 0.6 & - & - & 0.5 \\
\hline $\begin{array}{l}\text { Temperature Coef- } \\
\text { ficient }(\% \mathrm{RH} / \mathrm{C})\end{array}$ & - & 0.05 & 0.04 & $-0.0032(\mathrm{RH}+22)$ \\
\hline $\begin{array}{l}\text { Long Term Stability } \\
\text { (\% RH / year) }\end{array}$ & 1.0 & 1.0 & 1.0 & - \\
\hline Time Response (sec) & 10 & 5 & $15^{*}$ & 16 \\
\hline Cost & $\$ 795$ & - & $\$ 465$ & $\$ 425$ \\
\hline
\end{tabular}

* With membrane filter, otherwise 5 seconds with plastic grid.

- Indicates information not supplied or available from manufacturer. 
Table 3: Manufacturers' Specifications of Impedance Sensors

\begin{tabular}{lccc} 
& $\begin{array}{c}\text { General } \\
\text { Eastern } \\
850\end{array}$ & $\begin{array}{c}\text { Thunder } \\
\text { Scientific } \\
\text { PC-2101 }\end{array}$ & $\begin{array}{c}\text { Phys-Chem } \\
\text { PCRC-11 }\end{array}$ \\
\hline Range (\% RH) & $0-99$ & $5-90$ & $0-100$ \\
Accuracy (\% RH) & $\begin{array}{c}2.0 \text { from } \\
15-99 \% \text { RH }\end{array}$ & 2.0 & 2.0 \\
Resolution (\% RH) & 0.1 & 0.1 & - \\
Hysteresis (\% RH) & Negligible & - & 2.5 \\
Repeatability (\% RH) & 0.5 & - & - \\
$\begin{array}{c}\text { Temperature Coef- } \\
\text { ficient (\% RH / C) }\end{array}$ & 0.4 & - & - \\
$\begin{array}{c}\text { Long Term Stability } \\
\text { (\% RH / year) }\end{array}$ & 1.0 & - & - \\
$\begin{array}{l}\text { Time Response (sec) } \\
\text { Cost }\end{array}$ & 10 & - & 30 \\
\hline
\end{tabular}

- Indicates information not supplied or available from manufacturer. 


\section{Table 4:}

Calibration coefficients for Hy-Cal Engineering Ultra-H relative humidity sensors (with WHOI electronics) using

$$
R H=A 0+A 1 * P+A 2 * P^{2}+A 3 * P^{3}
$$

where $R H$ is the relative humidity and $P$ is the period output of the sensor in microseconds. Number of points (NPTS) in calibration are given as well as the root mean square (rms) error of calibration fit.

$\mathrm{S} / \mathrm{N} 2$

\begin{tabular}{rccrccc} 
Date & NPTS & $\begin{array}{c}\text { rms } \\
\text { error }\end{array}$ & A0 & A1 & A2 & A3 \\
\hline 11 MAY 88 & 21 & 0.26 & 9848.92 & -169.1099 & 0.9563874 & -0.001772362 \\
13 MAY 88 & 17 & 0.22 & 7484.44 & -129.7161 & 0.7379899 & -0.001369393 \\
8 JUN 88 & 19 & 0.31 & 4717.74 & -90.86442 & 0.5699986 & -0.001153879 \\
9 JUN 88 & 14 & 0.39 & 4324.93 & -83.62976 & 0.5256191 & -0.001063310 \\
30 AUG 88 & 14 & 0.48 & 6608.49 & -111.4337 & 0.6165954 & -0.001111363 \\
25 JUL 89 & 15 & 0.59 & -12064.8 & 207.2576 & -1.195914 & 0.002324374 \\
\hline
\end{tabular}

$\mathrm{S} / \mathrm{N} 3$

\begin{tabular}{rcccccc} 
Date & NPTS & error & A0 & A1 & A2 & A3 \\
\hline 11 MAY 88 & 21 & 0.30 & 8135.31 & -154.4271 & 0.9634806 & -0.001963614 \\
13 MAY 88 & 17 & 0.25 & 6471.24 & -123.8643 & 0.7767117 & -0.001583802 \\
1 JUN 88 & 20 & 0.50 & 3460.14 & -68.22168 & 0.4348848 & -0.0008844079 \\
30 AUG 88 & 14 & 0.44 & 7883.69 & -146.9576 & 0.9009881 & -0.001805726 \\
25 JUL 89 & 15 & 0.63 & -11725.2 & 222.3659 & -1.417133 & 0.003043820 \\
\hline
\end{tabular}




\section{Table 5:}

Calibration coefficients for Vaisala HMP-14U Humicap relative humidity sensors (with WHOI electronics) using

$$
R H=A 0+A 1 * P+A 2 * P^{2}+A 3 * P^{3}
$$

where $R H$ is the relative humidity and $P$ is the period output of the sensor in microseconds. Number of points (NPTS) in calibration are given as well as the root mean square (rms) error of calibration fit.

\section{S/N A}

\begin{tabular}{ccccccc} 
Date & NPTS & error & A0 & A1 & A2 & \multicolumn{1}{c}{ A3 } \\
\hline 19 SEP 86 & 12 & 0.27 & -20549.0 & -291.7842 & 1.358655 & -0.002075063 \\
24 NOV 87 & 13 & 0.40 & -29898.6 & 354.1600 & -1.395482 & 0.001834977 \\
07 JAN 88 & 21 & 0.63 & -14579.0 & 165.5504 & -0.6225206 & 0.0007802570 \\
28 JAN 88 & 20 & 0.56 & -20647.4 & 242.4594 & -0.9467252 & 0.001234929 \\
20 JAN 89 & 14 & 4.62 & -6085.54 & 64.69168 & -0.2247931 & 0.0002589427 \\
\hline
\end{tabular}

S/N B

\begin{tabular}{ccccccl}
\multicolumn{7}{c}{ rms } \\
Date & NPTS & error & A0 & A1 & A2 & \multicolumn{1}{c}{ A3 } \\
\hline 19 SEP 86 & 14 & 0.30 & 0922.7 & -294.8328 & 1.362857 & -0.002066605 \\
24 NOV 87 & 13 & 0.32 & 17762.7 & -258.0525 & 1.222866 & -0.001893128 \\
28 JAN 88 & 20 & 0.23 & -3799.07 & 25.27780 & -0.01569232 & -0.00009226493 \\
\hline
\end{tabular}




\section{Table 6:}

Calibration coefficients for Vaisala HMP-35A relative humidity sensors using

$$
R H=A 0+A 1 * V+A 2 * V^{2}+A 3 * V^{3}
$$

where $R H$ is the relative humidity and $V$ is the voltage output of the sensor. Number of points (NPTS) in calibration are given as well as the root mean square (rms) error of calibration fit.

\section{$\mathrm{S} / \mathrm{N} 287852$}

\begin{tabular}{cccrrrr} 
Date & NPTS & error & A0 & A1 & A2 & A3 \\
\hline & & & & & & \\
4 MAY 89 & 13 & 0.44 & -10.45 & 145.71 & -93.21 & 60.10 \\
17 OCT 89 & 17 & 0.38 & -0.60 & 92.34 & 3.81 & 3.06 \\
14 NOV 89 & 18 & 0.34 & 0.03 & 85.43 & 17.23 & -5.93 \\
12 DEC 89 & 18 & 0.43 & 7.17 & 51.22 & 66.19 & -28.34 \\
6 MAR 90 & 19 & 0.37 & -1.78 & 107.06 & -28.75 & 19.54 \\
\hline
\end{tabular}

$\mathrm{S} / \mathrm{N} 287855$

\begin{tabular}{cccrrrr} 
Date & NPTS & $\begin{array}{c}\text { rms } \\
\text { error }\end{array}$ & A0 & A1 & A2 & A3 \\
\hline 4 MAY 89 & 13 & 0.44 & -12.35 & 157.15 & -114.42 & 73.16 \\
17 OCT 89 & 16 & 0.38 & 0.69 & 82.31 & 24.26 & -9.88 \\
14 NOV 89 & 18 & 0.39 & -0.77 & 89.04 & 10.52 & -2.61 \\
12 DEC 89 & 18 & 0.41 & 7.26 & 49.51 & 70.17 & -31.57 \\
6 MAR 90 & 19 & 0.35 & -01.65 & 103.87 & -21.81 & 14.51 \\
\hline
\end{tabular}




\section{Table 7:}

Calibration coefficients for Rotronic MP-100F relative humidity sensors using

$$
R H=A 0+A 1 * V+A 2 * V^{2}+A 3 * V^{3}
$$

where $R H$ is the relative humidity and $V$ is the voltage output of the sensor. Number of points (NPTS) in calibration are given as well as the root mean square (rms) error of calibration fit.

$$
\mathrm{S} / \mathrm{N} 02388
$$

\begin{tabular}{rccrrrr} 
Date & NPTS & $\begin{array}{c}\text { rms } \\
\text { error }\end{array}$ & A0 & A1 & A2 & A3 \\
\hline 13 MAR 87 & 12 & 0.32 & -1.69 & 108.74 & -24.99 & 8.35 \\
5 JUN 87 & 16 & 0.24 & 3.29 & 86.25 & 16.92 & -14.90 \\
13 MAY 88 & 17 & 0.36 & -3.20 & 99.21 & 3.37 & -8.14 \\
30 AUG 88 & 14 & 0.38 & -3.45 & 110.56 & -27.49 & 19.54 \\
4 MAY 89 & 15 & 0.19 & -0.64 & 83.84 & 13.02 & 1.07 \\
\hline \multicolumn{7}{c}{ S/N 02392 }
\end{tabular}

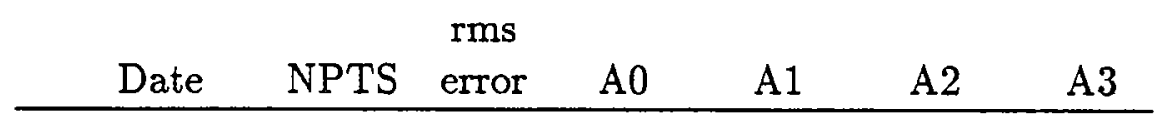

\begin{tabular}{rrrrrrr} 
17 OCT 86 & 17 & 0.40 & -0.31 & 105.39 & -13.90 & 6.49 \\
13 MAR 87 & 12 & 0.17 & -1.45 & 123.78 & -57.95 & 29.06 \\
5 JUN 87 & 16 & 0.39 & 2.09 & 113.27 & -39.02 & 17.98 \\
30 AUG 88 & 14 & 0.34 & -3.45 & 121.20 & -48.40 & 31.30 \\
28 MAR 89 & 15 & 0.16 & -1.80 & 113.52 & -37.82 & 24.36 \\
4 MAY 89 & 15 & 0.25 & 3.53 & 77.43 & 23.72 & -8.22 \\
\hline \multicolumn{7}{c}{ S/N 11378 }
\end{tabular}

\begin{tabular}{ccccccc} 
Date & NPTS & $\begin{array}{c}\text { rms } \\
\text { error }\end{array}$ & A0 & A1 & A2 & A3 \\
\hline & & & & & & \\
1 JUN 88 & 20 & 0.25 & -2.07 & 105.76 & -18.42 & 11.05 \\
30 AUG 88 & 14 & 0.30 & -3.52 & 113.32 & -40.28 & 29.05 \\
\hline
\end{tabular}


Table 7

(continued)

S/N 16301

\begin{tabular}{rccrrrr} 
Date & NPTS & $\begin{array}{c}\text { rms } \\
\text { error }\end{array}$ & A0 & A1 & A2 & A3 \\
\hline 23 MAY 89 & 17 & 0.19 & -3.22 & 110.58 & -20.57 & 13.15 \\
3 JUL 89 & 17 & 0.30 & -4.93 & 128.52 & -76.85 & 63.13 \\
7 JUL 89 & 15 & 0.39 & -9.92 & 154.63 & -132.04 & 93.26 \\
8 AUG 89 & 17 & 0.33 & -4.91 & 118.77 & -40.75 & 29.18 \\
6 SEP 89 & 18 & 0.25 & -3.78 & 112.68 & -42.97 & 37.30 \\
17 OCT 89 & 17 & 0.16 & -0.76 & 82.92 & 16.73 & -4.35 \\
14 NOV 89 & 18 & 0.23 & -4.33 & 105.65 & -22.55 & 14.78 \\
12 DEC 89 & 18 & 0.37 & 6.22 & 56.85 & 55.09 & -24.84 \\
6 MAR 90 & 20 & 0.19 & -1.79 & 108.20 & -24.28 & 9.52 \\
\hline
\end{tabular}

S/N 16302

rms

\begin{tabular}{rccrrrr} 
Date & NPTS & error & A0 & A1 & A2 & A3 \\
\hline 23 MAY 89 & 17 & 0.16 & -4.74 & 119.97 & -37.59 & 21.94 \\
3 JUL 89 & 16 & 0.23 & -10.17 & 157.78 & -124.63 & 85.51 \\
7 JUL 89 & 15 & 0.42 & -11.34 & 164.70 & -150.60 & 103.24 \\
8 AUG 89 & 17 & 0.47 & -5.30 & 126.39 & -51.77 & 32.20 \\
6 SEP 89 & 18 & 0.60 & -4.26 & 133.47 & -81.76 & 56.39 \\
17 OCT 89 & 17 & 0.20 & -1.26 & 89.17 & 1.46 & 6.49 \\
14 NOV 89 & 18 & 0.25 & -2.71 & 100.81 & -18.08 & 15.30 \\
12 DEC 89 & 18 & 0.33 & 7.60 & 45.34 & 75.11 & -33.28 \\
6 MAR 90 & 20 & 0.24 & 2.13 & 96.74 & -22.17 & 17.52 \\
\hline
\end{tabular}


Table 8:

Calibration coefficients for General Eastern 850 relative humidity sensors using

$$
R H=A 0+A 1 * V+A 2 * V^{2}+A 3 * V^{3}
$$

where $R H$ is the relative humidity and $V$ is the voltage output of the sensor. Number of points (NPTS) in calibration are given as well as the root mean square (rms) error of calibration fit.

\section{$\mathrm{S} / \mathrm{N} 846$}

\begin{tabular}{rccrrrl} 
Date & NPTS & $\begin{array}{c}\text { rms } \\
\text { error }\end{array}$ & A0 & A1 & A2 & A3 \\
\hline 23 MAY 89 & 17 & 0.59 & -58.91 & 58.90 & -11.23 & 1.15 \\
3 JUL 89 & 16 & 0.70 & -55.96 & 58.54 & -11.64 & 1.23 \\
7 JUL 89 & 16 & 0.54 & -77.27 & 82.18 & -20.22 & 2.17 \\
8 AUG 89 & 17 & 0.56 & -68.81 & 63.00 & -11.48 & 1.10 \\
6 SEP 89 & 18 & 0.40 & -63.80 & 62.08 & -12.17 & 1.24 \\
17 OCT 89 & 16 & 0.38 & -51.87 & 51.108 & -8.842 & 0.8801 \\
14 NOV 89 & 18 & 0.61 & -57.12 & 53.510 & -8.901 & 0.8263 \\
12 DEC 89 & 18 & 0.53 & -37.68 & 38.293 & -4.887 & 0.4792 \\
6 MAR 90 & 18 & 0.65 & -40.90 & 44.603 & -6.903 & 0.6590 \\
\hline
\end{tabular}

$\mathrm{S} / \mathrm{N} 946$

\begin{tabular}{rrrrrrl} 
Date & NPTS & $\begin{array}{c}\text { rms } \\
\text { error }\end{array}$ & A0 & A1 & A2 & A3 \\
\hline 23 MAY 89 & 17 & 0.52 & -82.51 & 74.21 & -14.50 & 1.39 \\
3 JUL 89 & 16 & 0.60 & -85.85 & 84.45 & -19.72 & 2.11 \\
7 JUL 89 & 16 & 0.53 & -89.94 & 88.00 & -20.90 & 2.19 \\
8 AUG 89 & 17 & 0.69 & -61.45 & 61.60 & -12.02 & 1.20 \\
6 SEP 89 & 18 & 0.52 & -60.26 & 64.64 & -13.98 & 1.47 \\
17 OCT 89 & 17 & 0.54 & -55.35 & 58.652 & -11.886 & 1.2017 \\
14 NOV 89 & 18 & 0.71 & -51.48 & 53.063 & -9.680 & 0.9447 \\
12 DEC 89 & 18 & 0.48 & -26.77 & 32.541 & -4.084 & 0.4562 \\
6 MAR 90 & 18 & 0.73 & -36.28 & 44.244 & -7.551 & 0.7612 \\
\hline
\end{tabular}



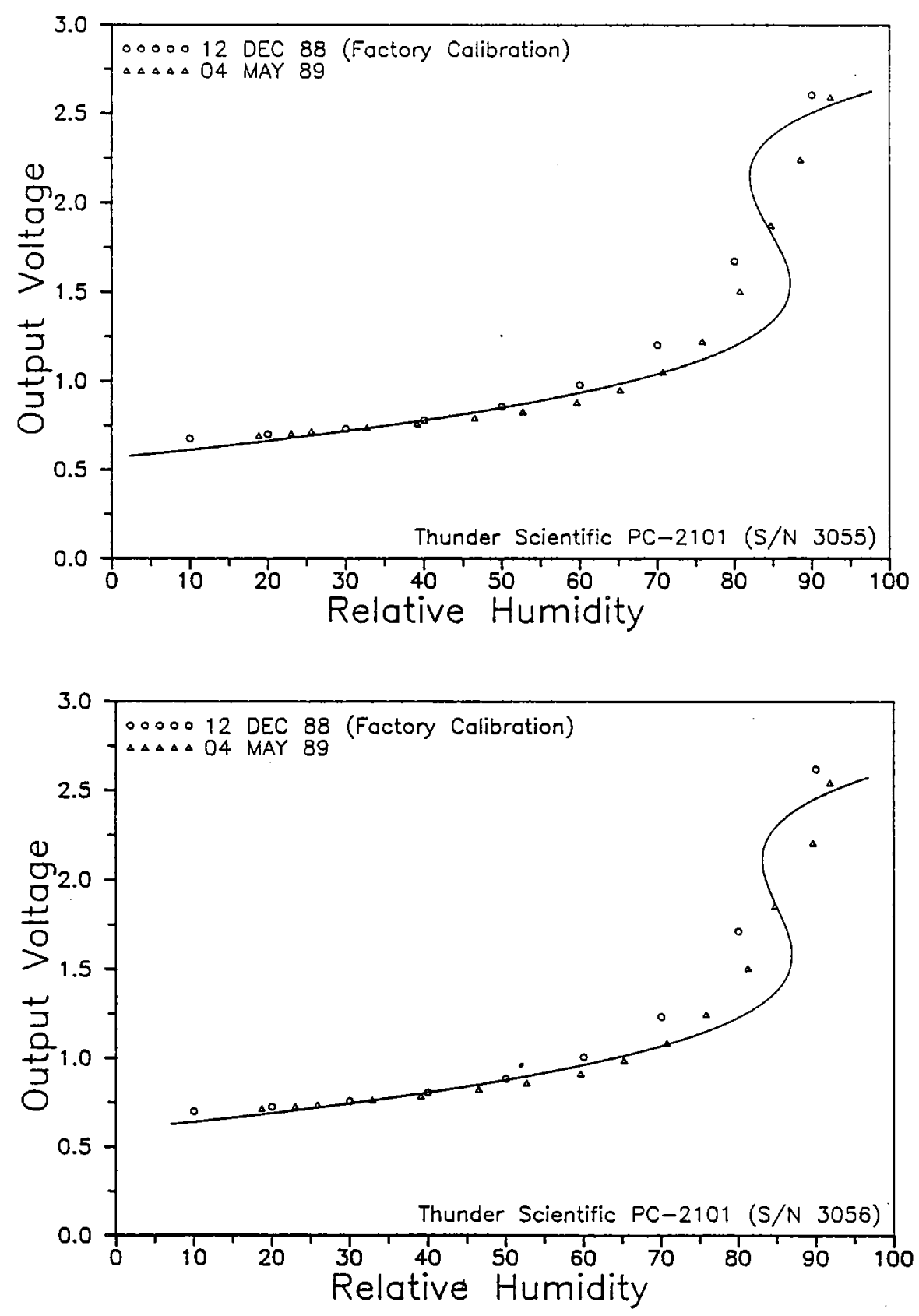

Figure 1: Calibration curves for Thunder Scientific PC-2101 relative humidity sensor (S/N 3055 and 3056). Circles are calibration points determined at factory and squares are calibration points determined at WHOI. Curve is a third order polynomial fit for WHOI calibration. 


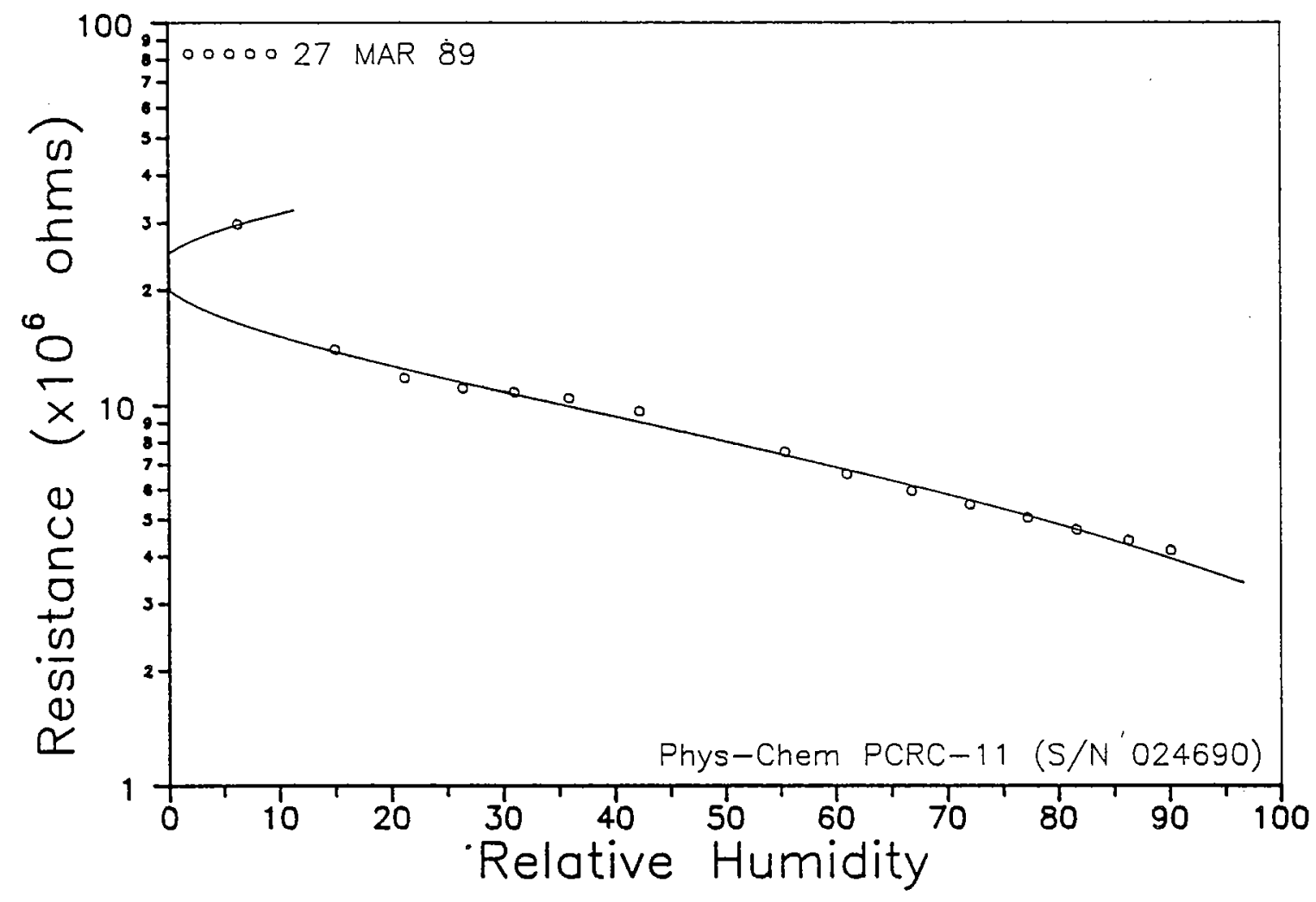

Figure 2: Calibration curve for Phys-Chem PCRC-11 relative humidity sensor. Note that third order polynomial fit is inadequate for relative humidities below $20 \% \mathrm{RH}$. 


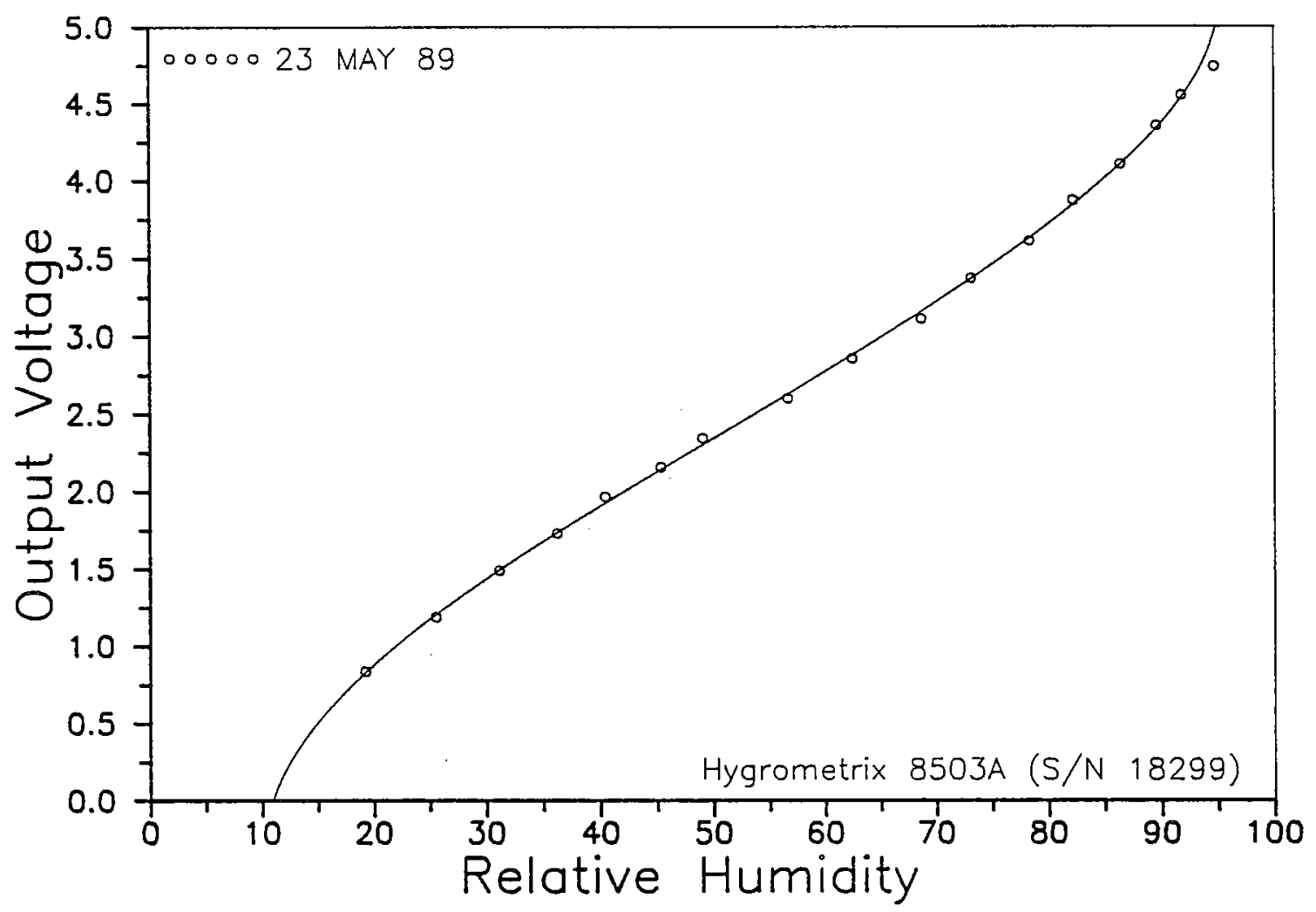

Figure 3: Calibration curve for Hygrometrix 8503A relative humidity sensor (S/N 18299). 


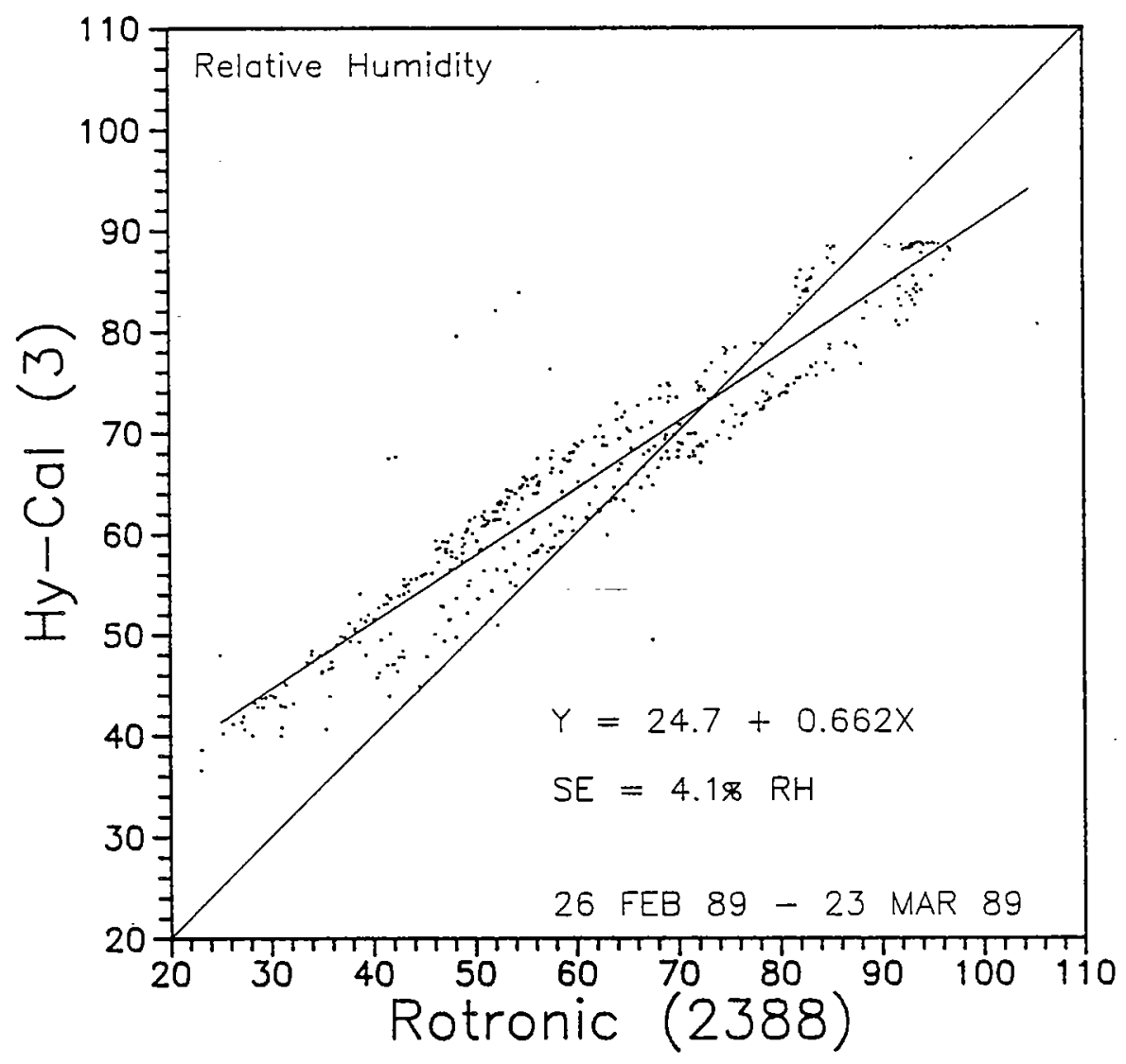

Figure 4: Scatter plot of a Hy-Cal Engineering relative humidity sensor (S/N 3) compared against a Rotronic MP-100F sensor (S/N 02388) from 26 February 1989 to 23 March 1989. Least squares fit and standard error of fit are given. 

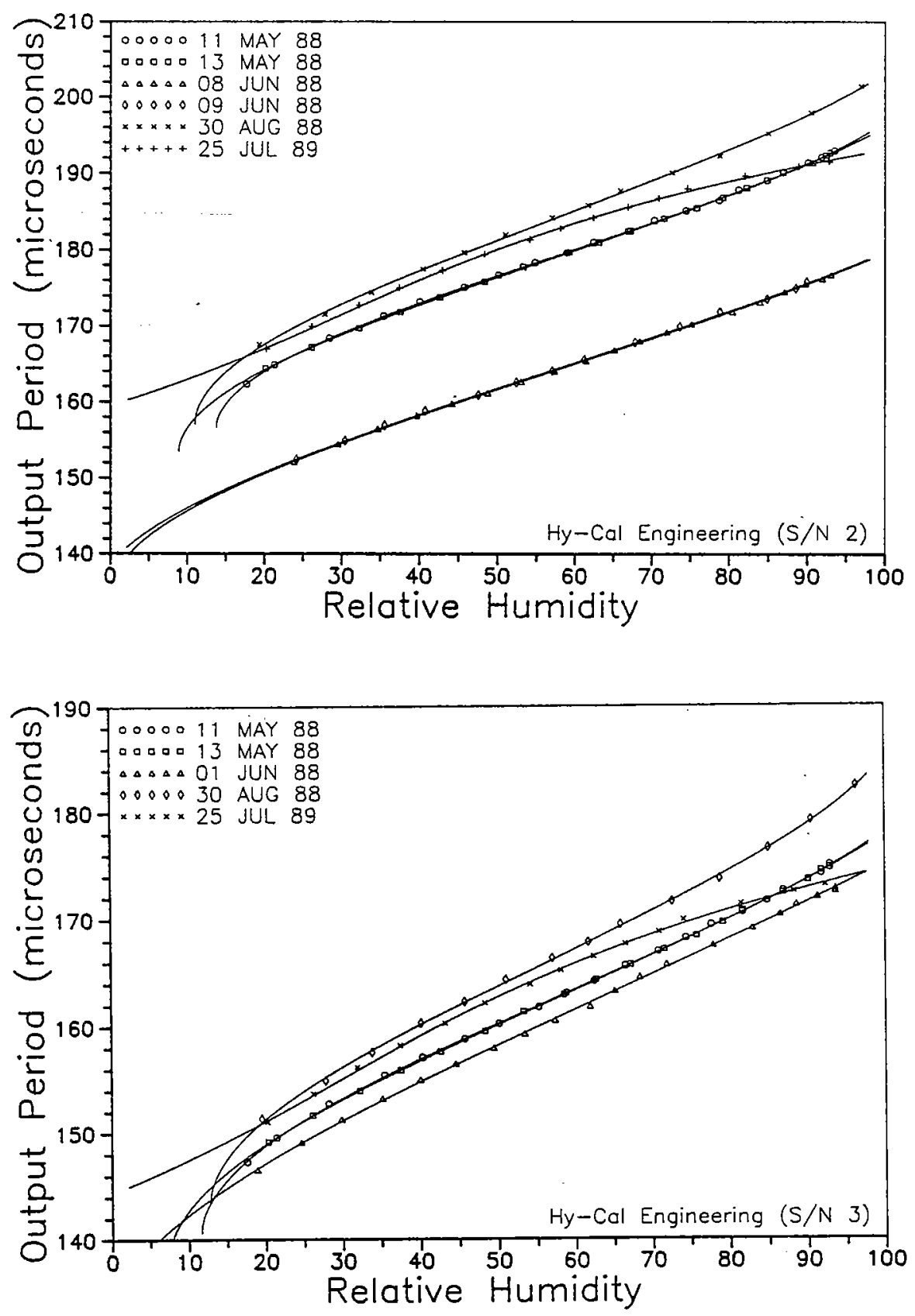

Figure 5: Calibration curves for Hy-Cal Engineering relative humidity sensors (S/N 2 and 3). Each point represents a calibration point and each curve is a third order polynomial fit for each calibration run. 

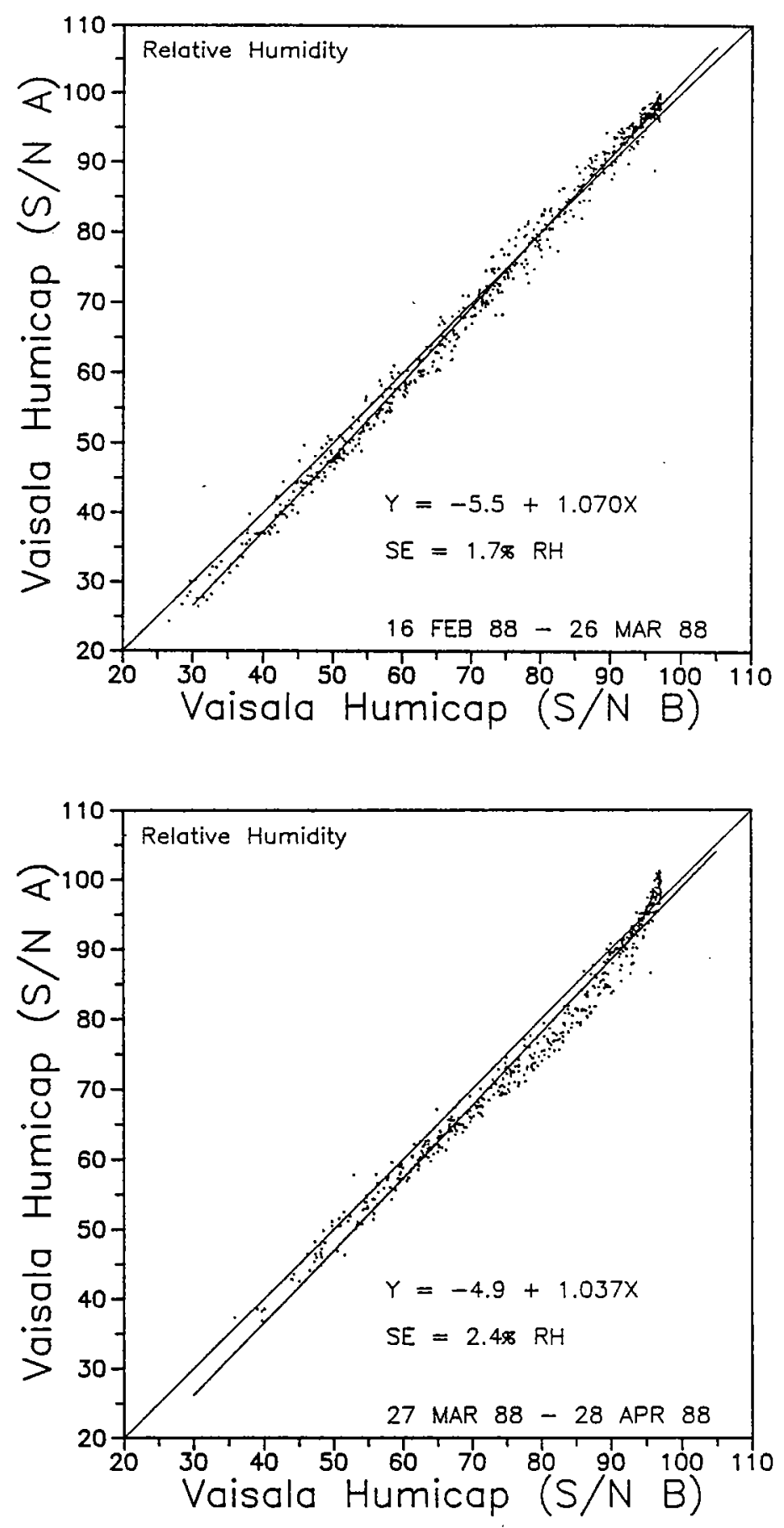

Figure 6: Scatter plots of two Vaisala Humicap relative humidity sensors (S/N A and B) from (a) 16 February 1988 to 26 March 1988 and from (b) 27 March 1988 to 28 April 1988. Least squares fit and standard error of fit are given for each plot. 

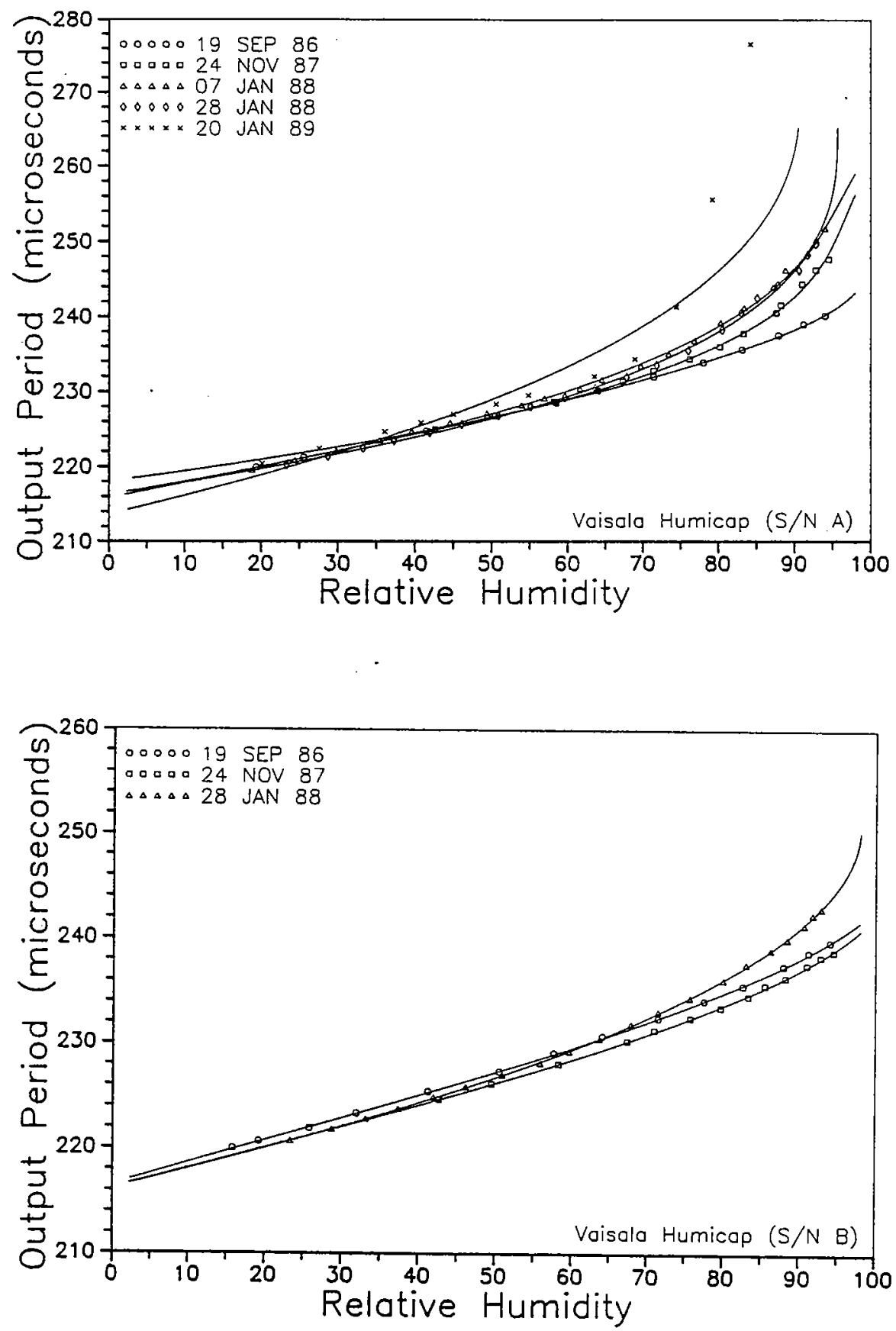

Figure 7: Calibration curves for Vaisala Humicap relative humidity sensors (S/N A and B). Fitted curves are third order polynomials. Note that sensor A shows insensitivity at humidities greater than $85 \% \mathrm{RH}$ for 20 January 1989 calibration. 

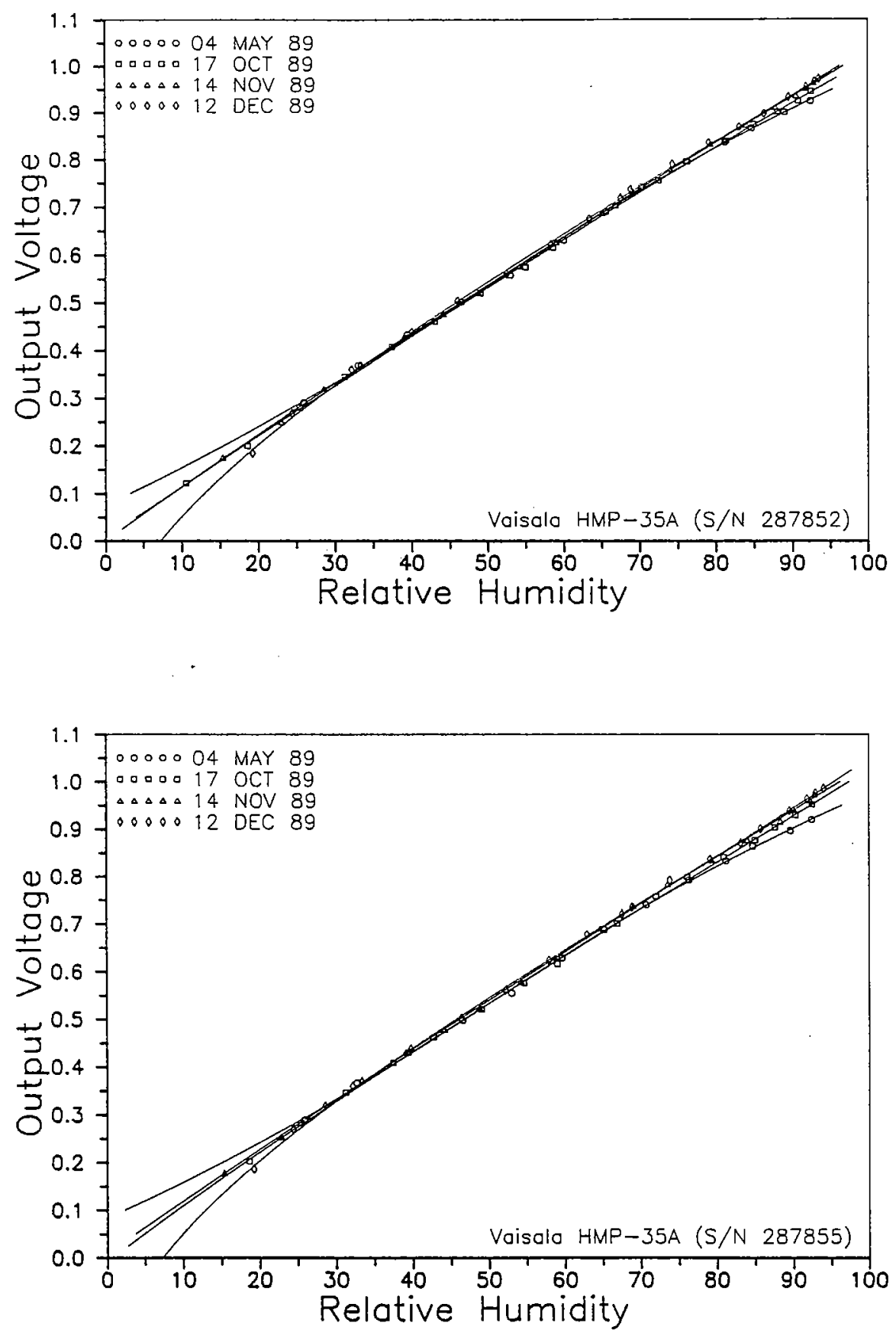

Figure 8: Calibration curves for Vaisala HMP-35A relative humidity sensors (S/N 287852 and 287855). 

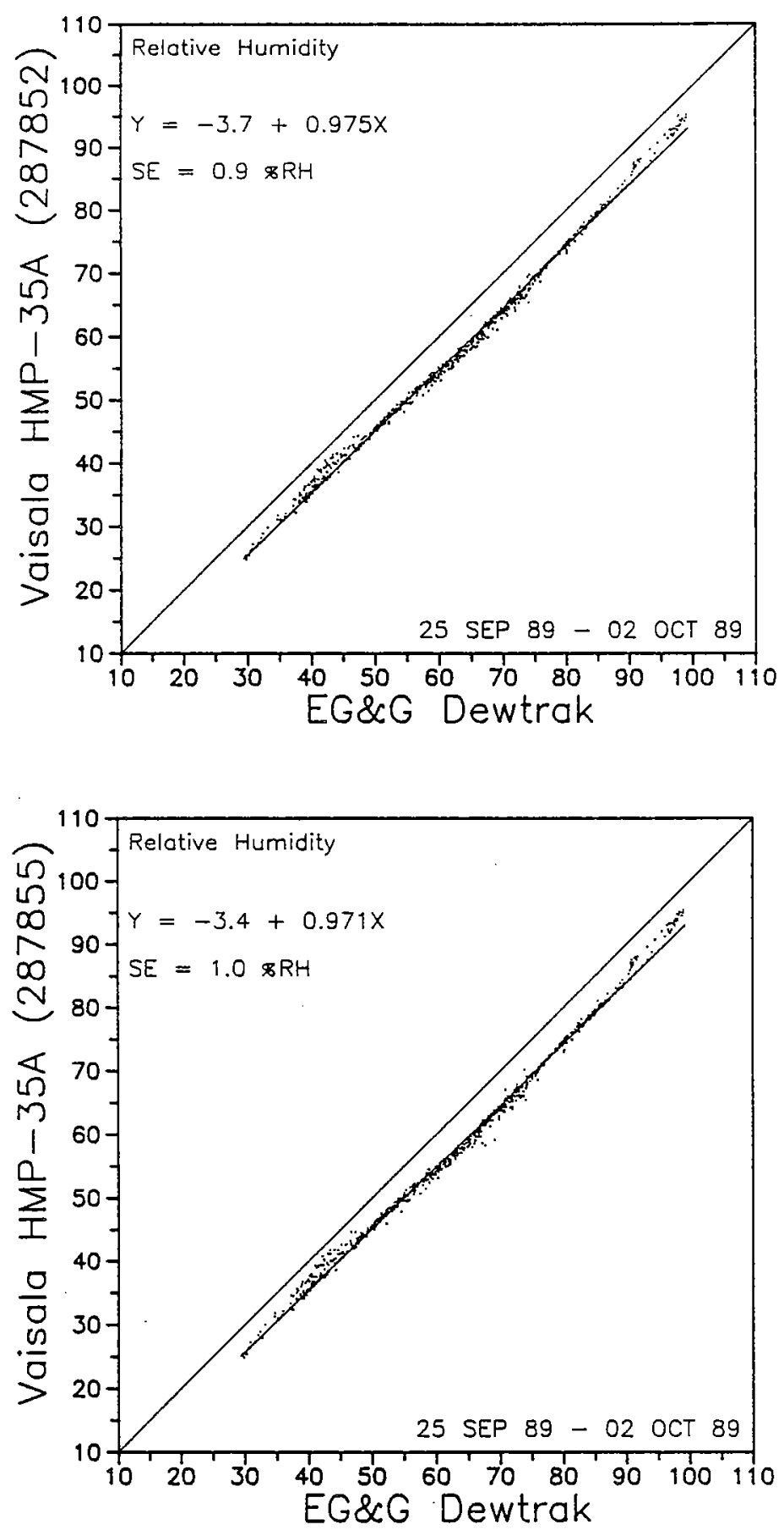

- Figure 9: Scatter plots for two Vaisala HMP-35A relative humidity sensors (S/N 287852 and 287855) for 25 September 1989 to 2 October 1989. Linear least squares fit and standard error are also given. 

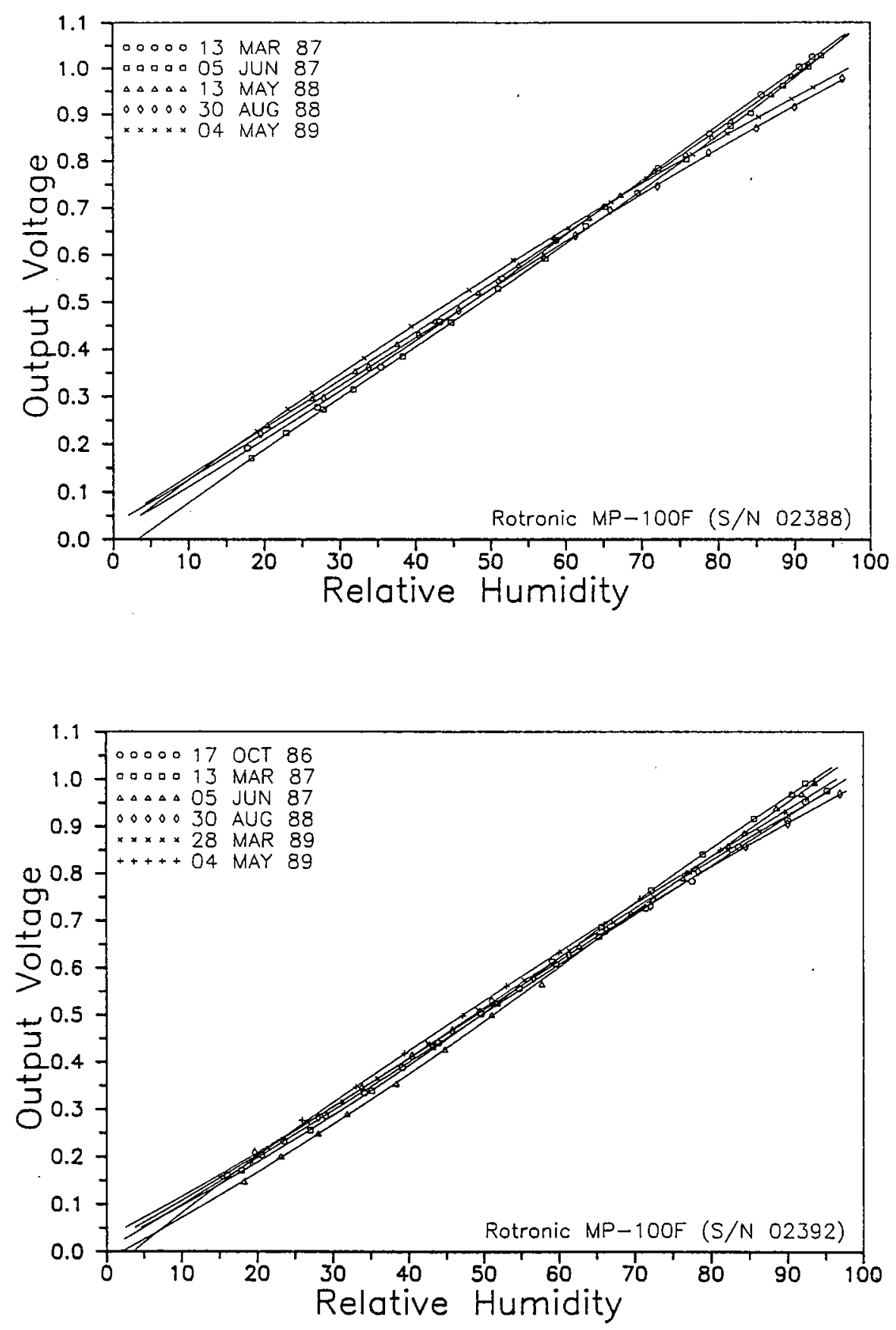

Figure 10: Calibration curves for Rotronic MP-100F relative humidity sensors (S/N 02388 and 02392). 

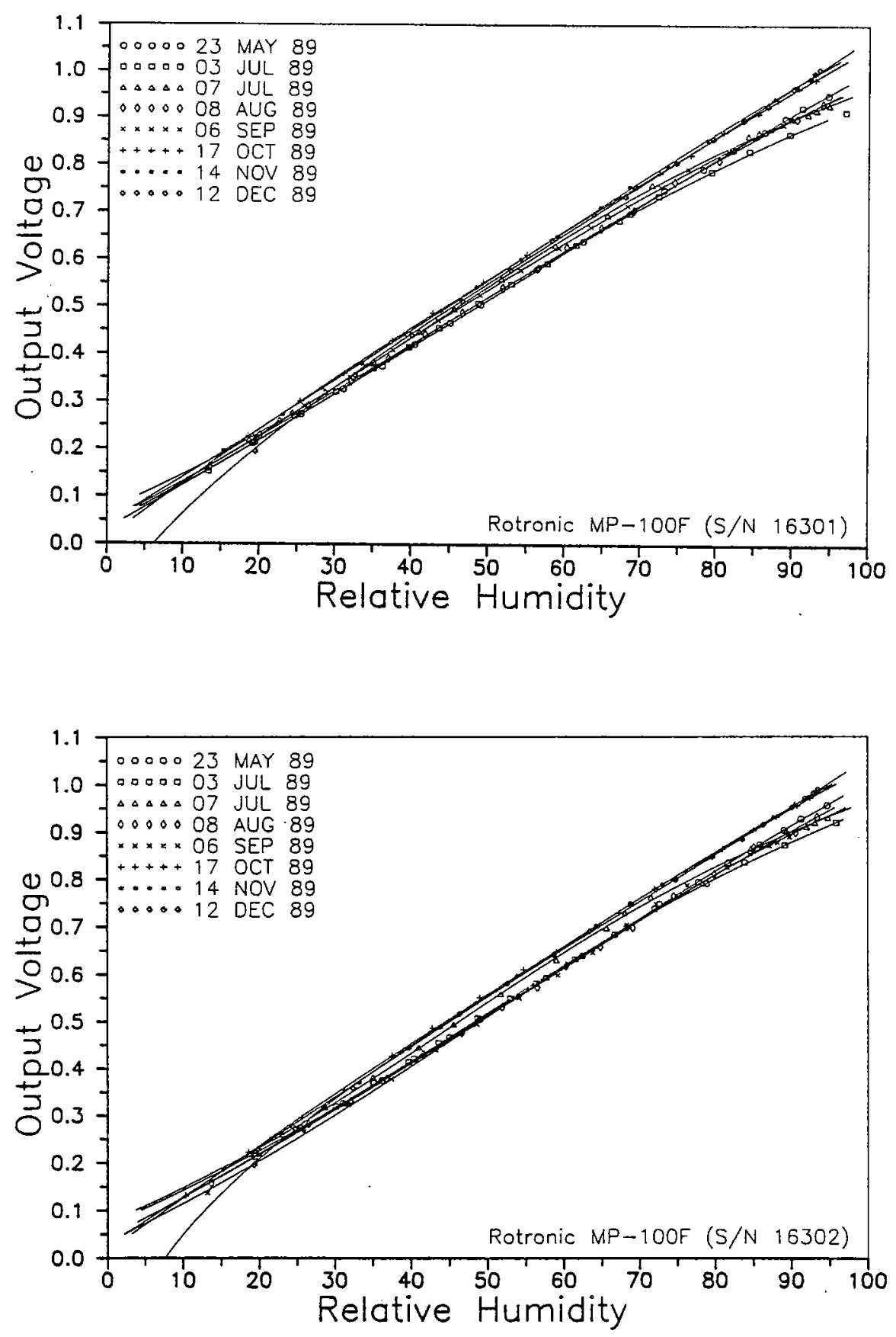

Figure 11: Calibration curves for Rotronic MP-100F relative humidity sensors (S/N 16301 and 16302). 

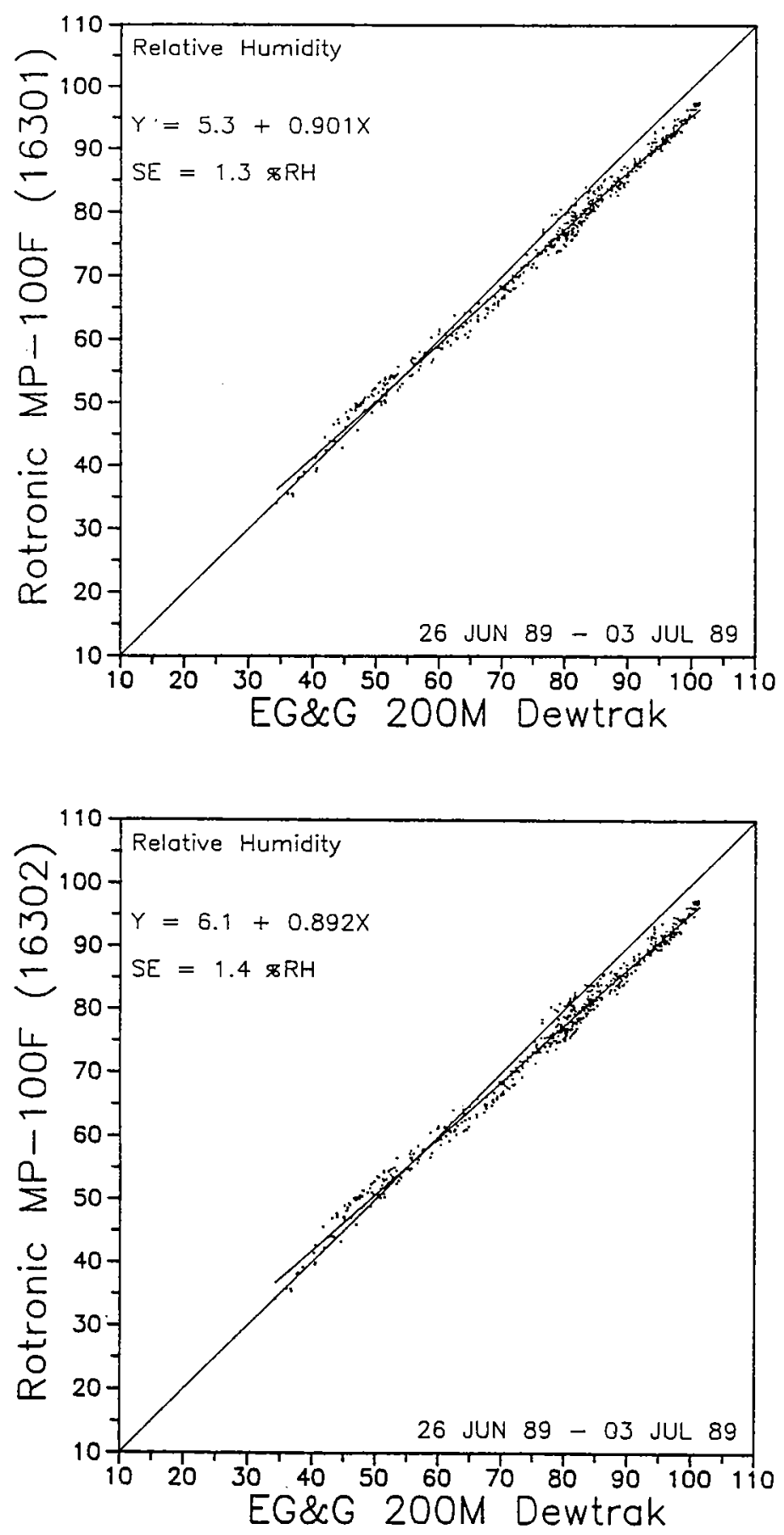

Figure 12: Scatter plots for two Rotronic MP-100F relative humidity sensors (S/N 16301 and S/N 16302) for 26 June 1989 to 3 July 1989. Linear least squares fit and standard error are also given. 

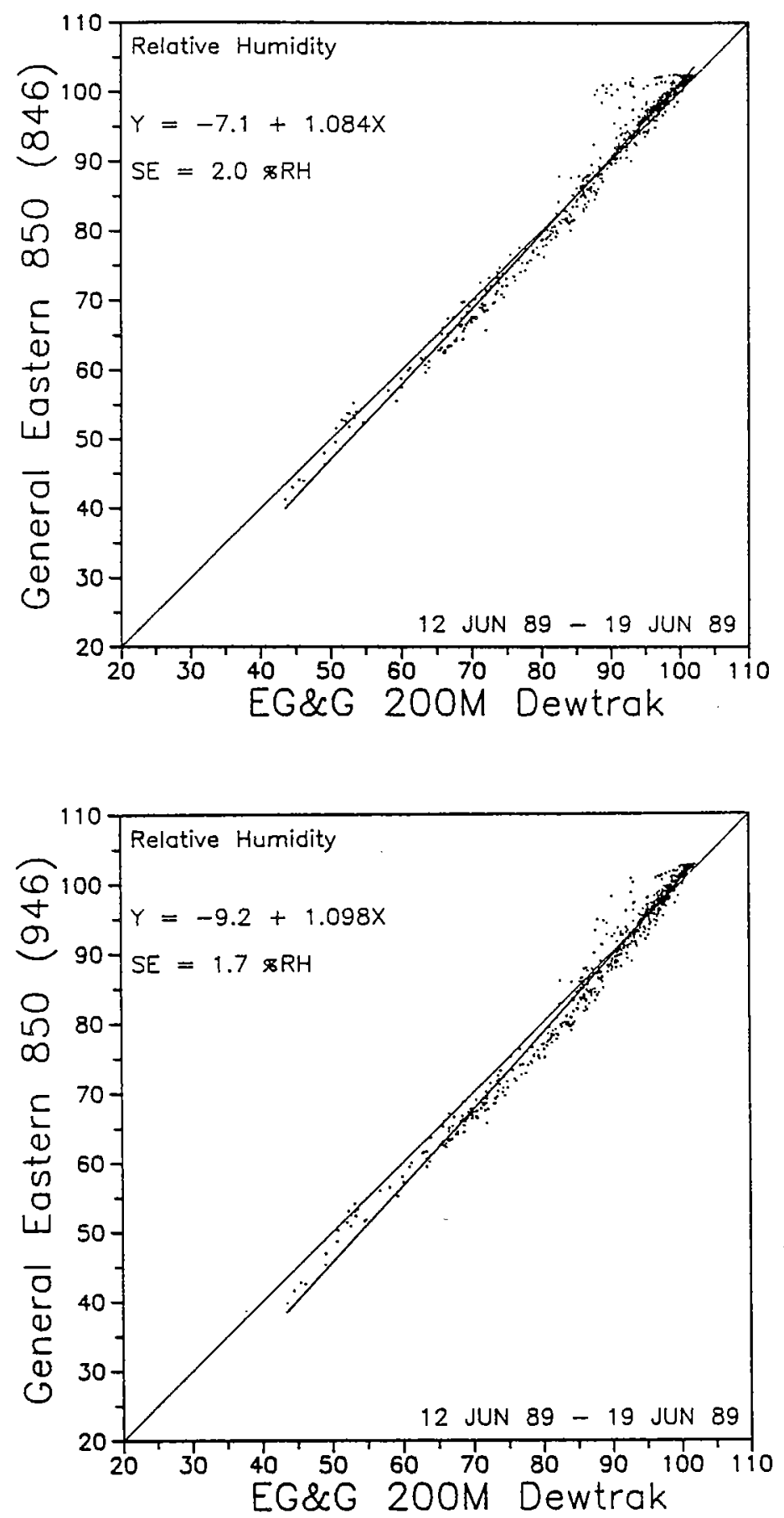

Figure 13: Scatter plots of General Eastern 850 relative humidity sensors (S/N 846 and 946) against an EG\&G Dewtrak from 12 June 1989 to 19 June 1989. Least squares fit and standard error are included. 

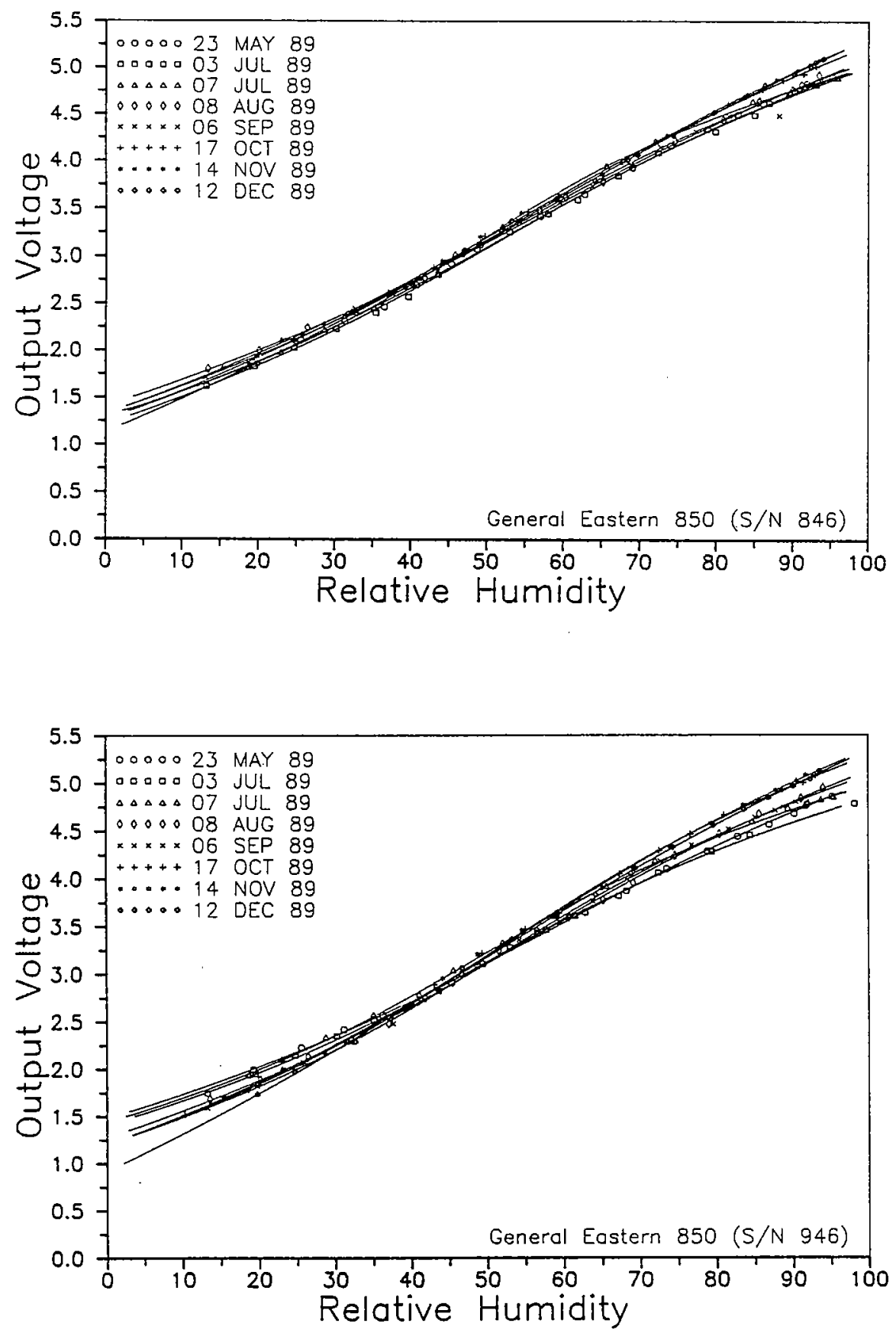

Figure 14: Calibration curves for General Eastern 850 relative humidity sensors (S/N 846 and 946$)$. 

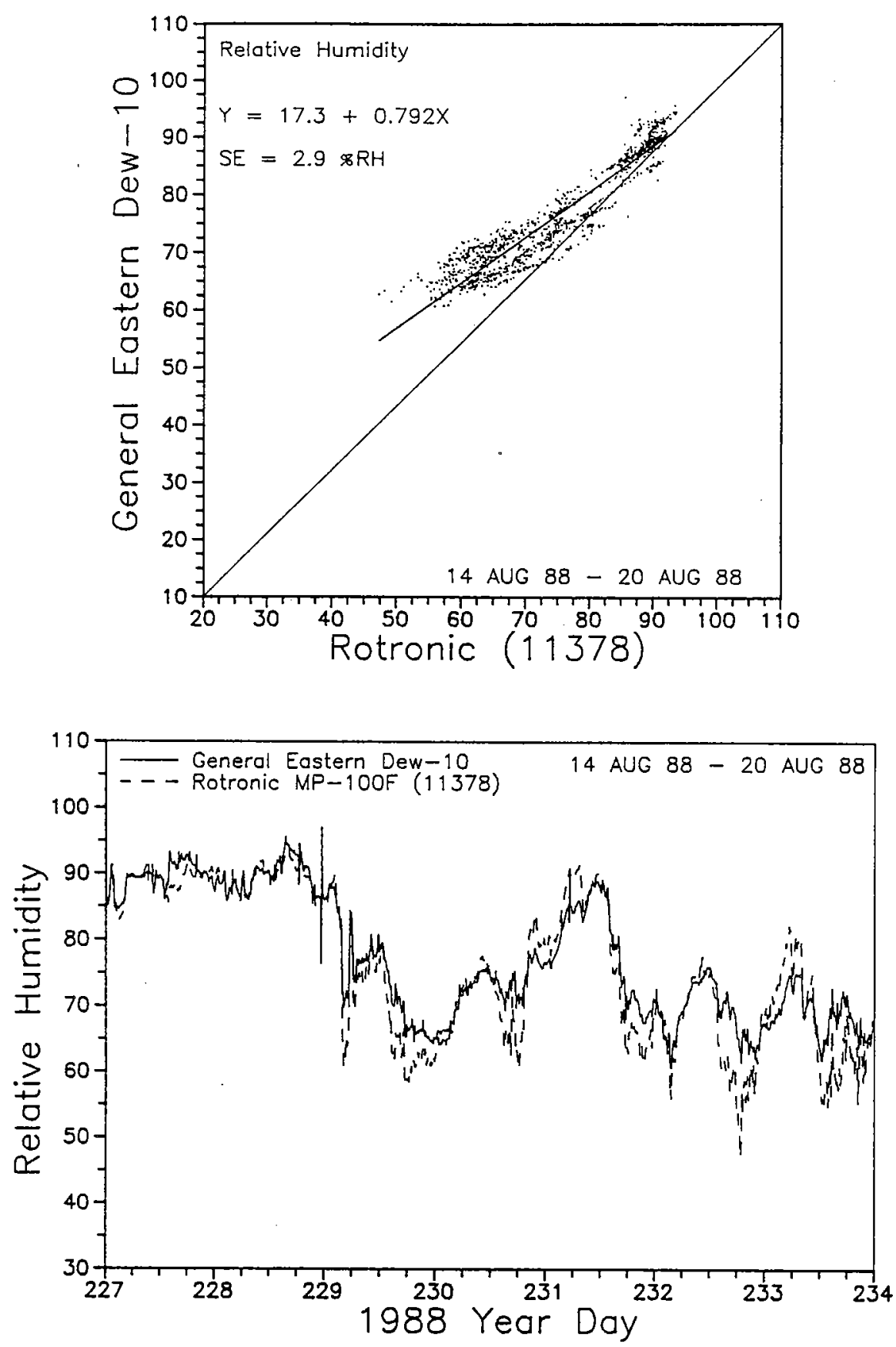

Figure 15: Time series (a) and scatter plot (b) of a General Eastern Dew-10 chilled mirror dew pointer and a Rotronic MP-100F relative humidity sensor (S/N 11378) from 14 August 1988 to 20 August 1988. Least squares fit and standard error are given in scatter plot. 

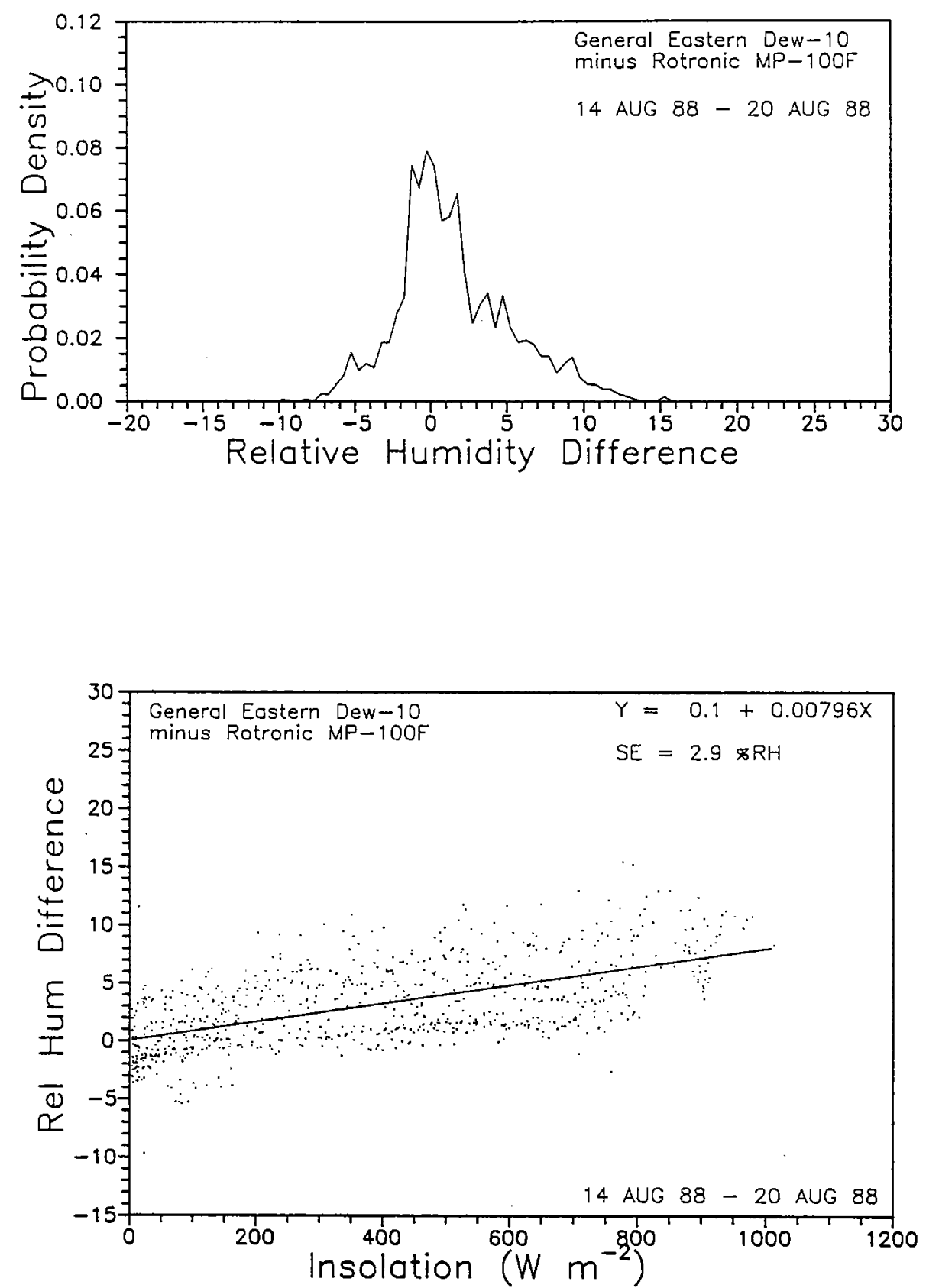

Figure 16: Probability density function (a) of the relative humidity difference between a General Eastern Dew-10 and a Rotronic MP-100F from 14 August 1988 to 20 August 1988. The relative humidity difference is also shown on a scatter plot (b) as a function of insolation. 

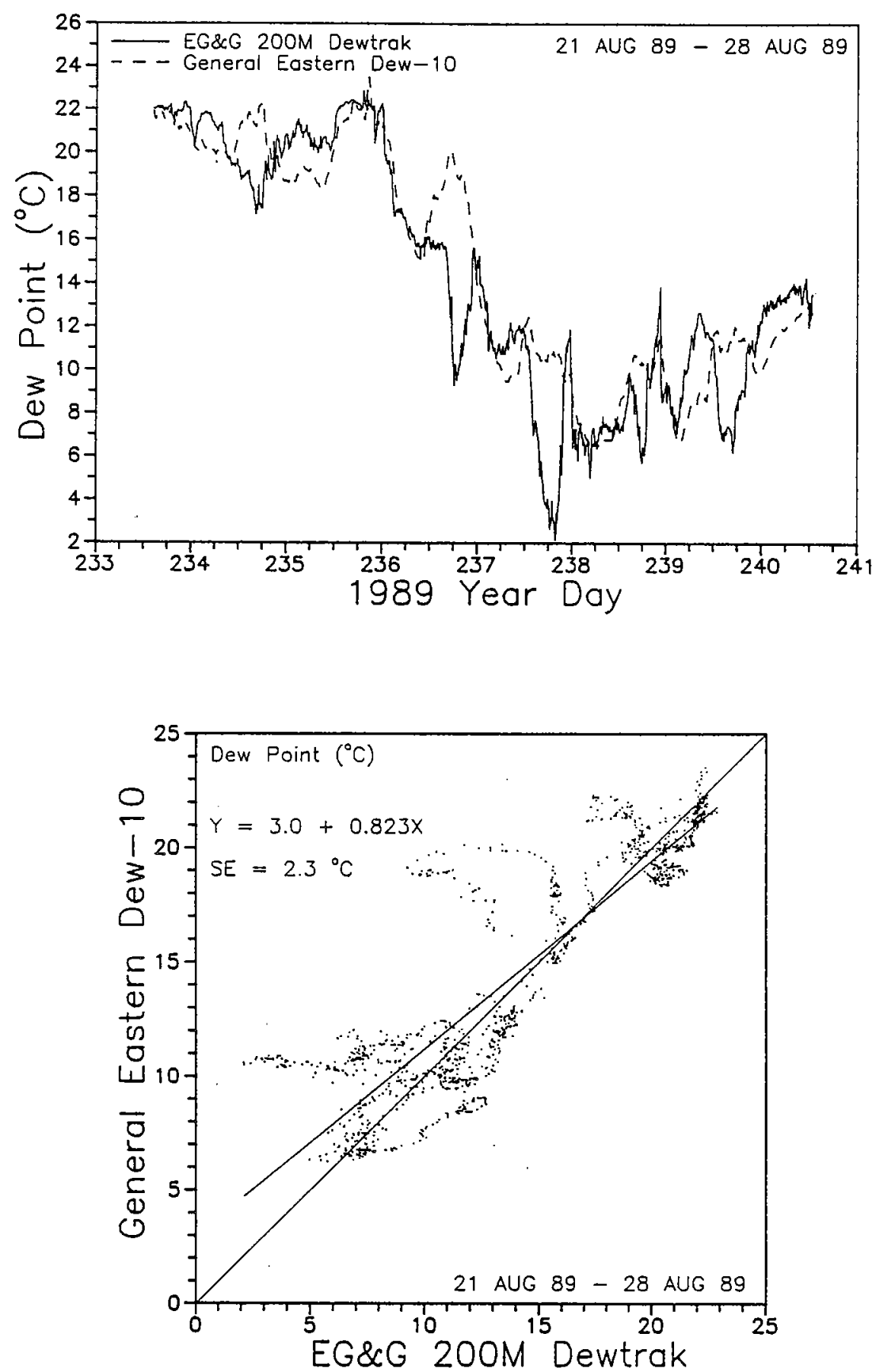

Figure 17: Time series (a) and scatter plot (b) of a General Eastern Dew-10 chilled mirror dew pointer and an EG\&G 200M Dewtrak chilled mirror dew pointer from 21 August 1989 to 28 August 1989. Least squares fit and standard error are given in scatter plot. 

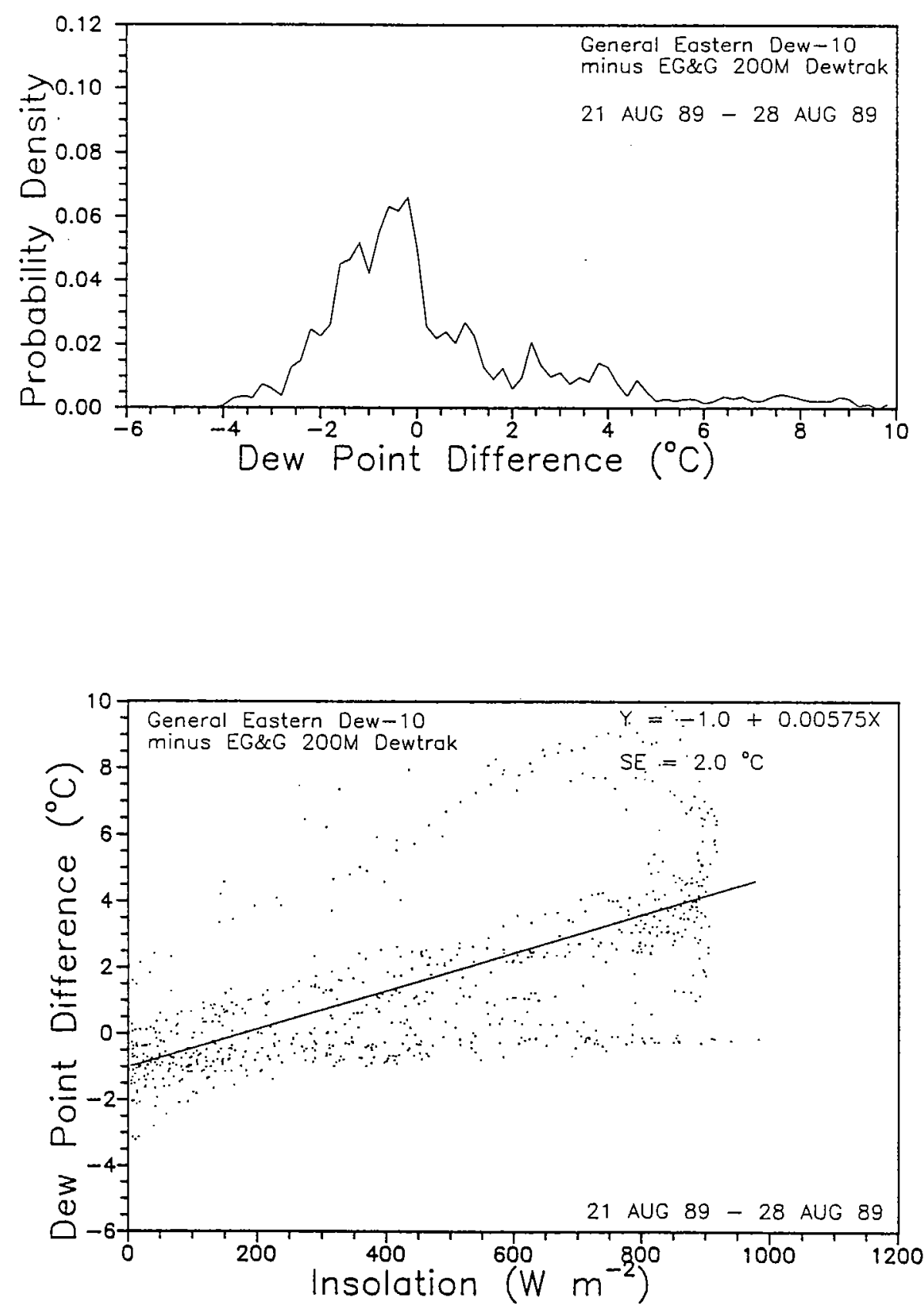

Figure 18: Probability density function (a) of the relative humidity difference between a General Eastern Dew-10 and an EG\&G 200M Dewtrak from 21 August 1989 to 28 August 1989 . The relative humidity difference is also shown on a scatter plot (b) as a function of insolation. 


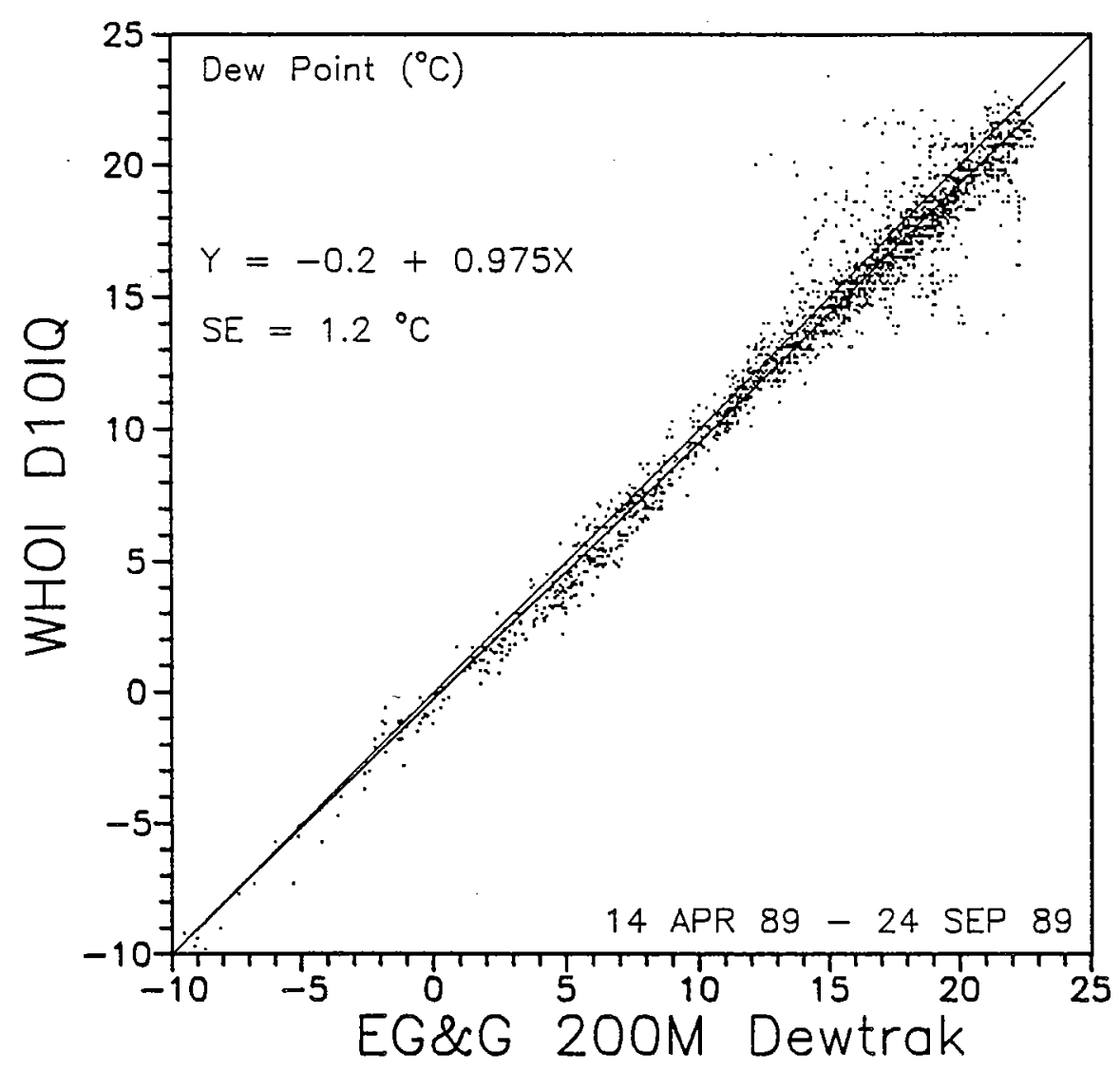

Figure 19: Scatter plot of WHOI D10IQ dew point sensor against an EG\&G 200M Dewtrak dew point sensor from 14 April 1989 to 5 September 1989. Linear least squares fit and standard error are also included. 


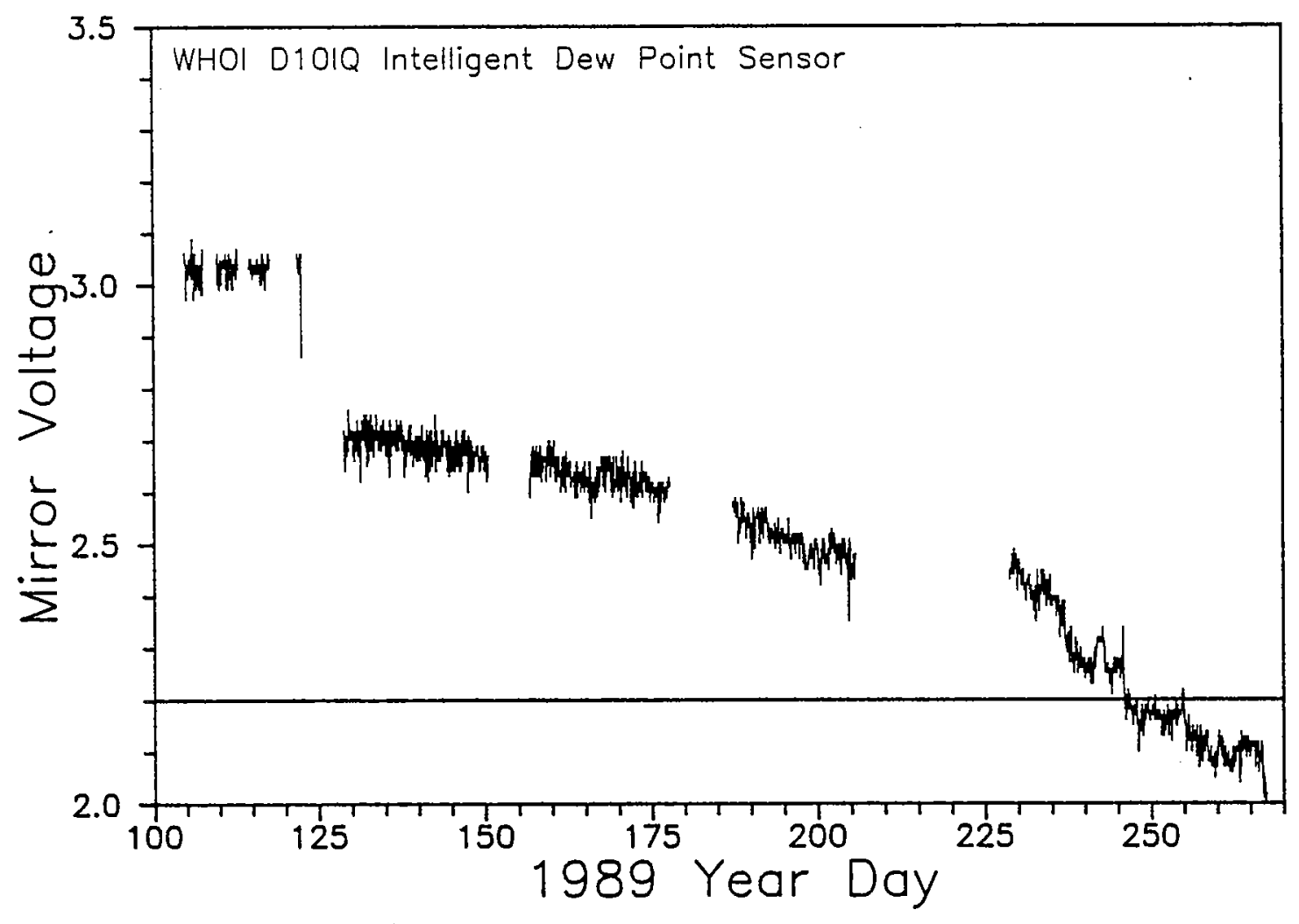

Figure 20: Time series plot of WHOI D10IQ mirror voltage. 


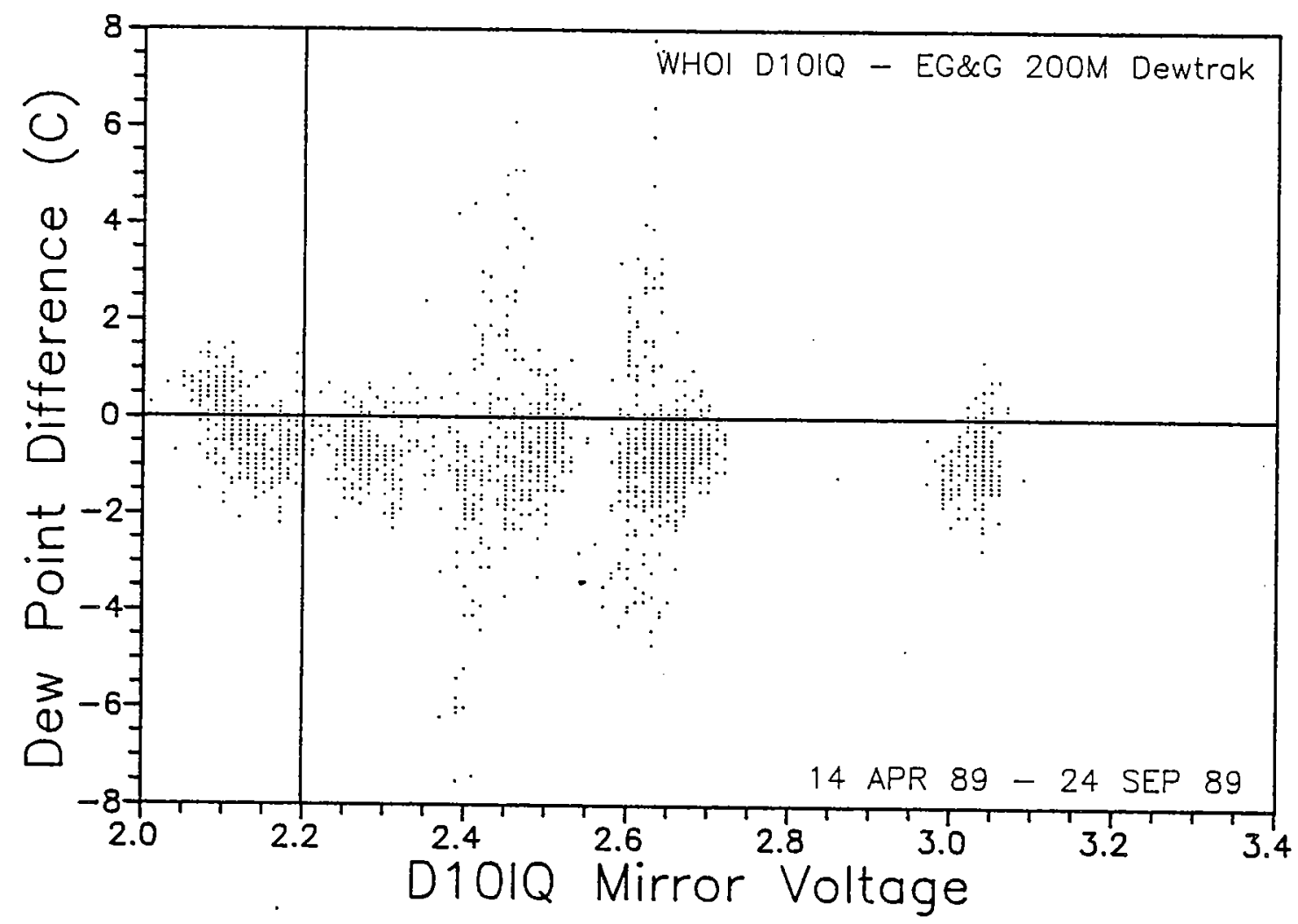

Figure 21: Scatter plot of the dew point difference (WHOI D10IQ minus the EG\&G $200 \mathrm{M}$ Dewtrak) as a function of the D10IQ mirror voltage. 


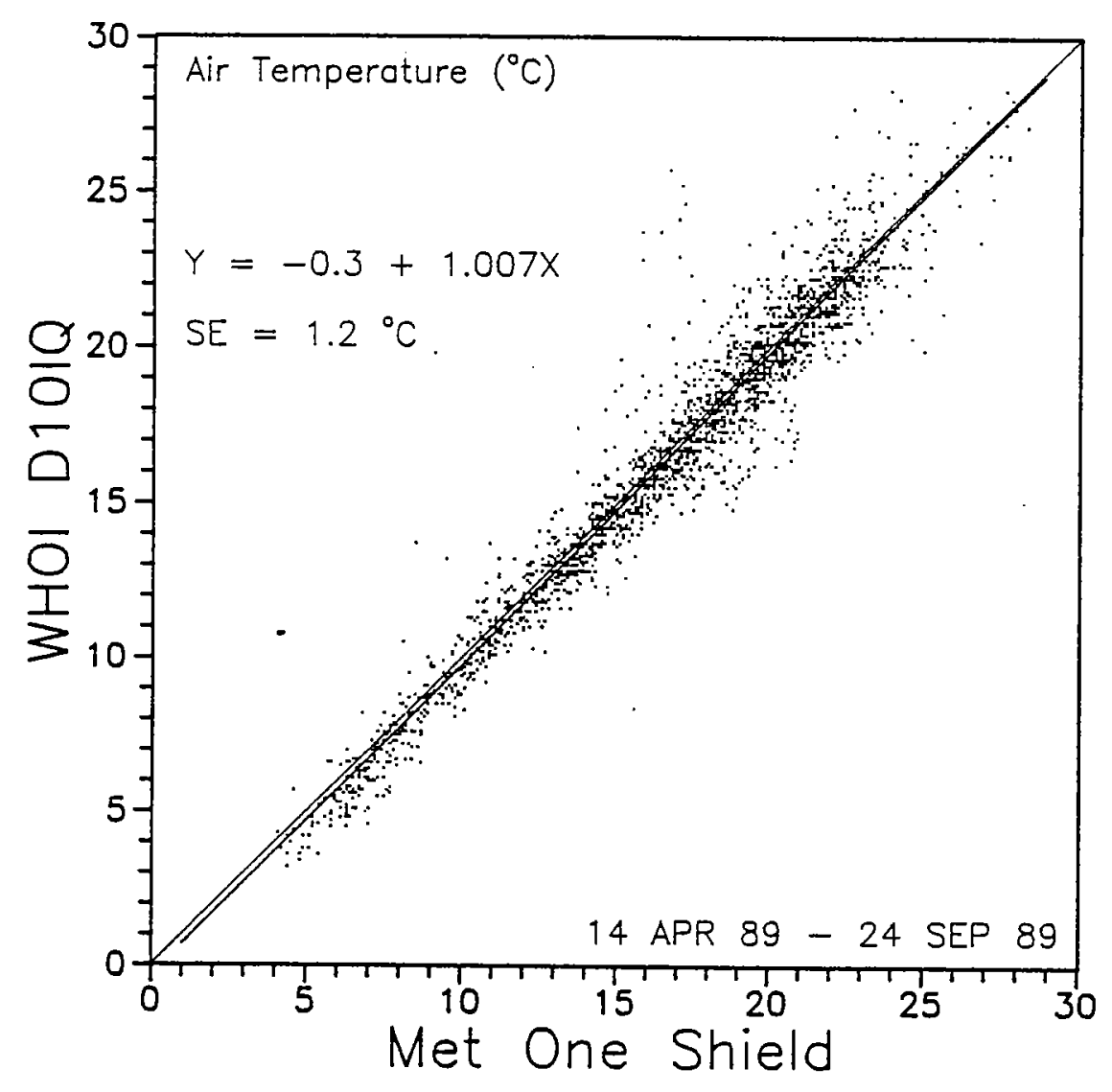

Figure 22: Scatter plot of air temperature data measured by the WHOI D10IQ and from a Met One fan ventilated radiation shield from 14 April 1989 to 24 September 1989. Least squares fit and standard error are given. 


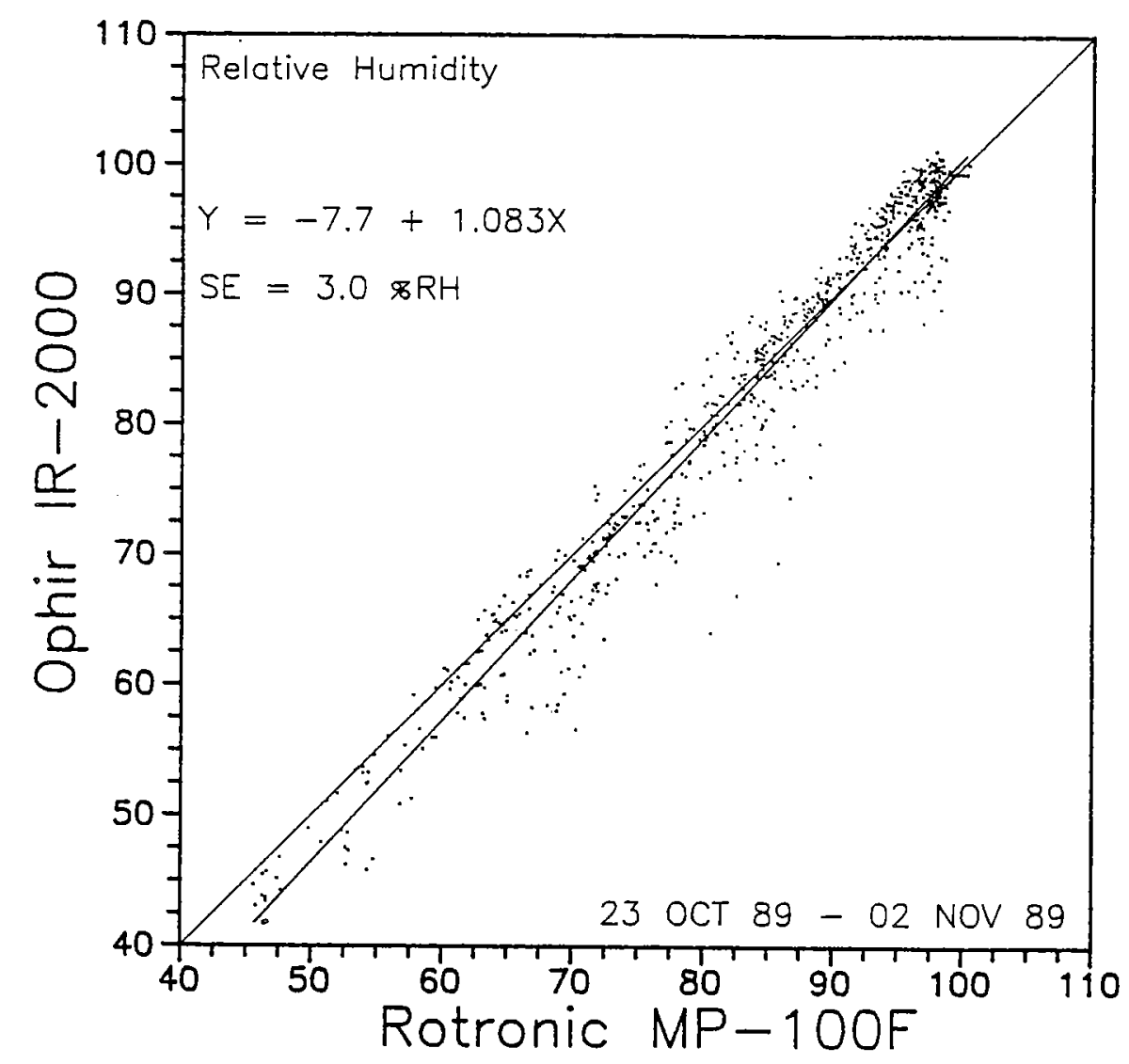

Figure 23: Scatter plot of the Ophir IR-200 infrared optical hygrometer against a Rotronic MP-100F relative humidity sensor from 23 October 1989 to 2 November 1989. These data were acquired just before the IR-2000 failed because of rain water penetration into the electronics assembly. 


\section{Appendix - Manufacturers' Addresses}

General Eastern Instruments

50 Hunt Street

Watertown, Massachusetts 02172

(617) $923-2386$

$\mathrm{Hy}-\mathrm{Cal}$ Engineering

9650 Telstar Avenue

El Monte, California 91731-3093

(818) 444-4000

Hygrometrix Inc.

7800 MacArthur Boulevard

Oakland, California 94605

(415) 639-7800

Ophir Corporation

3190 South Wadsworth Boulevard

Suite 100

Lakewood, Colorado 80227

(303) 986-1512

Phys-Chem Scientific Corporation

36 West 20th Street

New York, New York 10011

(212) 924-2070

Rotronic Instrument Corporation

7 High Street

Huntington, New York 11743

(516) 427-3994
Thunder Scientific Corporation 623 Wyoming S.E.

Albuquerque, New Mexico 87123 (505) 265-8701

Vaisala Inc.

2 Tower Office Park

Woburn, Massachusetts 01801

(617) $933-4500$ 


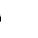




\section{DOCUMENT LIBRARY}

January 17, 1990

\section{Distribution List for Technical Report Exchange}

Attn: Stella Sanchez-Wade

Documents Section

Scripps Institution of Oceanography

Library, Mail Code C-075C

La Jolla, CA 92093

Hancock Library of Biology \&

Oceanography

Alan Hancock Laboratory

University of Southern California

University Park

Los Angeles, CA 90089-0371

Gifts \& Exchanges

Library

Bedford Institute of Oceanography

P.O. Box 1006

Dartmouth, NS, B2Y 4A2, CANADA

Office of the International

Ice Patrol

c/o Coast Guard R \& D Center

Avery Point

Groton, CT 06340

NOAA/EDIS Miami Library Center

4301 Rickenbacker Causeway

Miami, FL 33149

Library

Skidaway Institute of Oceanography

P.O. Box 13687

Savannah, GA 31416

Institute of Geophysics

University of Hawaii

Library Room 252

2525 Correa Road

Honolulu, HI 96822

Marine Resources Information Center

Building E38-320

MIT

Cambridge, MA 02139

Library

Lamont-Doherty Geological

Observatory

Columbia University

Palisades, NY 10964

Library

Serials Department

Oregon State University

Corvallis, OR 97331
Pell Marine Science Library

University of Rhode Island

Narragansett Bay Campus

Narragansett, RI 02882

Working Collection

Texas A\&M University

Dept. of Oceanography

College Station, TX 77843

Library

Virginia Institute of Marine Science

Gloucester Point, VA 23062

Fisheries-Oceänography Library

151 Oceanography Teaching Bldg.

University of Washington

Seattle, WA 98195

Library

R.S.M.A.S.

University of Miami

4600 Rickenbacker Causeway

Miami, FL 33149

Maury Oceanographic Library

Naval Oceanographic Office

Stennis Space Center

NSTL, MS 39522-5001

Marine Sciences Collection

Mayaguez Campus Library

University of Puerto Rico

Mayagues, Puerto Rico 00708

Library

Institute of Oceanographic Sciences

Deacon Laboratory

Wormley, Godalming

Surrey GU8 5UB

UNITED KINGDOM

The Librarian

CSIRO Marine Laboratories

G.P.O. Box 1538

Hobart, Tasmania

AUSTRALIA 7001

Library

Proudman Oceanographic Laboratory

Bidston Observatory

Birkenhead

Merseyside L43 7 RA

UNITED KINGDOM 
: .

. 


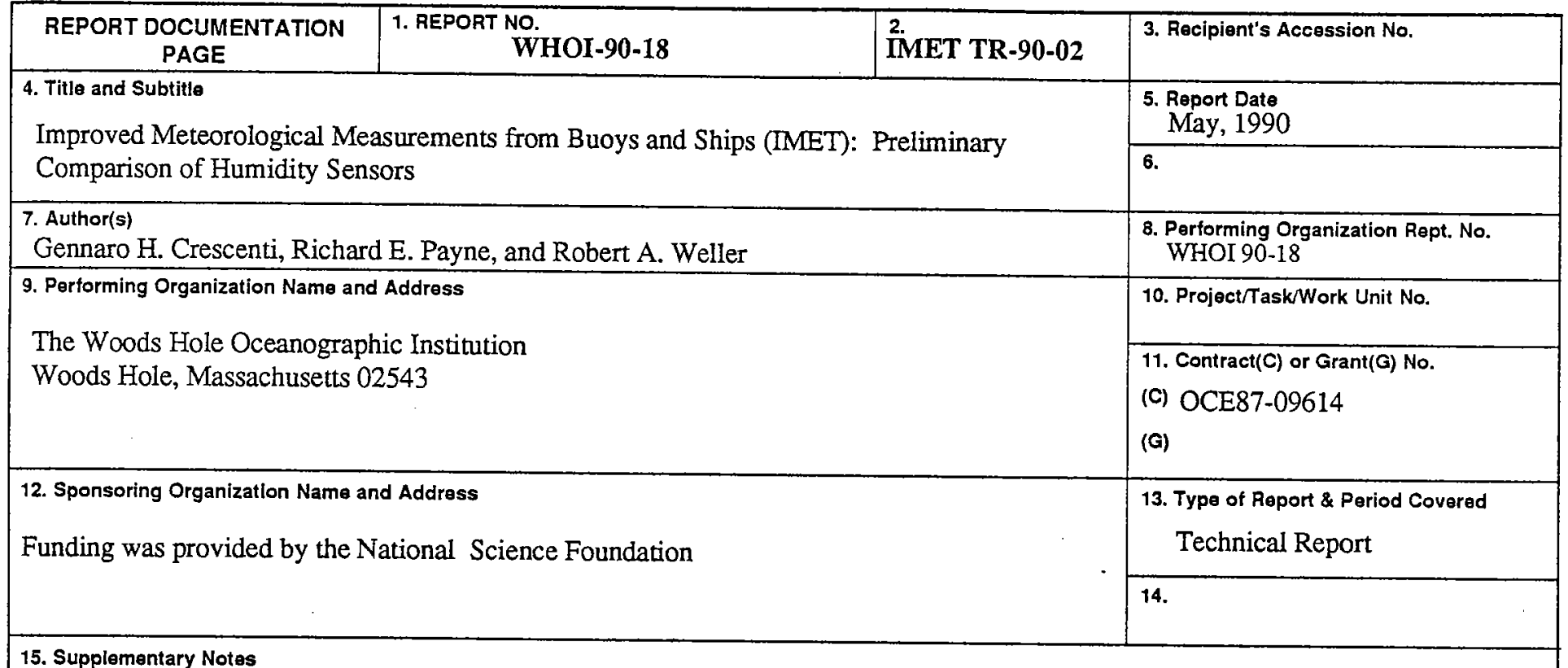

This report should be cited as: Woods Hole Oceanog. Inst. Tech. Rept., WHOI-90-18, IMET TR-90-02

16. Abstract (Limit: 200 words)

Humidity sensors using various principles of operation are evaluated for the potential use at sea on buoys and ships. Thin film capacitive polymer sensors include the Vaisala Humicap HMP-14U (with WHOI electronics), Hy-Cal Engineering Ultra-H (also with WHOI electronics), the new Vaisala HMP-35A, and the Rotronic MP-100F. Impedance sensors include the Thunder Scientific PC-2101, Phys-Chem PCRC-11, and the General Eastern 850 . The Hygrometrix 8503A is the only organically based cellulose crystallite sensor evaluated. Chilled mirror dew sensors include the EG\&G 200M Dewtrak, which was used as a comparative standard, the General Eastern Dew-10 and the WHOI D10IQ Intelligent Dew Point Sensor. The IR-200 infrared optical hygrometer from Ophir is also included in this study. The performance of the EG\&G 200M Dewtrak was quite disappointing. Errors of up to $2.5^{\circ} \mathrm{C}$ in air temperature were observed due to inadequate shielding from solar radiation.

\section{Document Analysis a. Descriptors}

1. humidity sensors

2. meteorological instrumentation

3. marine meteorology

b. Identiflers/Open-Ended Terms

c. COSATI Field/Group

18. Availability Statement

Approved for publication; distribution unlimited.

\begin{tabular}{|l|l|}
\hline $\begin{array}{c}\text { 19. Security Class (This Report) } \\
\text { UNCLASSIFIED }\end{array}$ & $\begin{array}{c}\text { 21. No. of Pages } \\
57\end{array}$ \\
\hline 20. Security Class (This Page) & 22. Price \\
\hline
\end{tabular}


